\title{
Obesity in Patients with Type I Diabetes: Links, Risks and Management Challenges
}

\author{
Nuria Vilarrasa $\mathbb{D}^{1,2}$ \\ Patricia San Jose ${ }^{1}$ \\ Miguel Ángel Rubio ${ }^{3}$ \\ Albert Lecube $2,4,5$ \\ 'Department of Endocrinology and \\ Nutrition, Hospital Universitario de \\ Bellvitge-IDIBELL, Barcelona, Spain; \\ ${ }^{2}$ CIBERDEM-CIBER de Diabetes \\ y Enfermedades Metabólicas Asociadas, \\ Instituto de Salud Carlos III, Madrid, \\ Spain; ${ }^{3}$ Department of Endocrinology \& \\ Nutrition, Hospital Clínico San Carlos, \\ IDISSC, Madrid, 28040, Spain; \\ ${ }^{4}$ Endocrinology and Nutrition \\ Department, Hospital Universitari Arnau \\ de Vilanova, Lleida, 25I98, Spain; \\ ${ }^{5}$ Obesity, Diabetes and Metabolism \\ (ODIM) Research Group, Institut de \\ Recerca Biomèdica de Lleida (IRBLleida), \\ University of Lleida, Lleida, Spain
}

Correspondence: Nuria Vilarrasa Hospital Universitario de BellvitgeIDIBELL, C/Feixa Llarga s/n, 08907 L'Hospitalet de Llobregat, Barcelona, Spain

Tel +34 93-53385II

Fax +34933375248

Email nuriavilarrasa@yahoo.es

\begin{abstract}
Obesity affects large numbers of patients with type 1 diabetes (T1D) across their lifetime, with rates ranging between $2.8 \%$ and $37.1 \%$. Patients with T1D and obesity are characterized by the presence of insulin resistance, of high insulin requirements, have a greater cardiometabolic risk and an enhanced risk of developing chronic complications when compared to normal-weight persons with T1D. Dual treatment of obesity and T1D is challenging and no specific guidelines for improving outcomes of both glycemic control and weight management have been established for this population. Nevertheless, although evidence is scarce, a comprehensive approach based on a balanced hypocaloric diet, physical activity and cognitive behavioral therapy by a multidisciplinary team, expert in both obesity and diabetes, remains as the best clinical practice. However, weight loss responses with lifestyle changes alone are limited, so in the "roadmap" of the treatment of obesity in T1D, it will be helpful to include anti-obesity pharmacotherapy despite at present there is a lack of evidence since T1D patients have been excluded from anti-obesity drug clinical trials. In case of severe obesity, bariatric surgery has proven to be of benefit in obtaining a substantial and long-term weight loss and reduction in cardiovascular risk. The near future looks promising with the development of new and more effective anti-obesity treatments and strategies to improve insulin resistance and oxidative stress. Advances in precision medicine may help individualize and optimize the medical management and care of these patients. This review, by gathering current evidence, highlights the need of solid knowledge in all facets of the treatment of patients with obesity and T1D that can only be obtained through high quality well-designed studies.
\end{abstract}

Keywords: obesity, type 1 diabetes, dual diabetes, insulin resistance, metabolic syndrome, bariatric surgery

\section{Introduction}

The prevalence of overweight and obesity in adults and children is continuously increasing worldwide and has doubled in more than 73 countries since $1980 .{ }^{1}$ Using the Global Burden of Disease study data, the estimated prevalence of obesity around the world in 2015 was $5.0 \%$ in children and $12.0 \%$ in adults, with high BMI accounting for 4 million deaths mainly due to cardiovascular disease. ${ }^{1}$ This dramatic increase in the prevalence of overweight and obesity affects patients with T1D which are especially vulnerable to excess weight. In this regard, increased BMI in T1D is associated with a greater cardiometabolic risk and enhanced development of chronic complications compared to lean patients with T1D. ${ }^{2}$ On the other hand, insulin resistance leads to high insulin requirements and hinders glycemic control and weight management. In the present review, we will 
summarize existing data on prevalence, trends, links and causes of obesity in patients with T1D.

Dual treatment of obesity and T1D is full of barriers and challenges as the equilibrium between intensified insulin therapy and optimal weight is difficult. Nowadays, no specific evidence-based guidelines for improving both glycemic control and weight management have been established for this population. In this paper, we will review the outcomes of specific nutritional, exercise and psychological strategies used in this clinical situation that may be useful to improve their care. For those patients unable to achieve a significant and sustained weight loss with lifestyle interventions, we will describe the evidence of adjunctive pharmacological treatments added to insulin, the potential benefits of approved anti-obesity drugs and the indications, outcomes and risks of bariatric surgery (BS). Also, in the near future new and more potent antiobesity drugs under development promise to facilitate the management of these patients. Our review highlights that although it is a growing problem, the knowledge in obesity approach in T1D is still very scarce, and therefore there is an urgent need for high quality designed studies from which evidence-based guidelines can be derived.

\section{Epidemiology of Obesity in Type I Diabetes}

How Often Does Obesity Appear in Type I Diabetes?

When dealing with a patient with obesity and diabetes, it is essential to make a proper classification into T1D or type 2 diabetes (T2D) as they are heterogeneous diseases with variable clinical presentation and disease progression. T1D is caused by autoimmune $\beta$-cell destruction, which leads to an absolute insulin deficiency, and insulin treatment is needed from the onset of the disease. On the other hand, T2D is due to peripheral insulin resistance and a progressive loss of adequate insulin secretion. ${ }^{3}$

Obesity affects large amounts of patients with T1D across their lifetime, with a prevalence that has increased during recent decades, and with rates ranging between $2.8 \%$ and $37.1 \% .{ }^{4}$ However, differences appear according to the definition of obesity, the age of the examined population, and the country. When obesity is defined as a body mass index $(\mathrm{BMI}) \geq 95$ th percentile, its prevalence ranges from $5.2 \%$ in Israel for the age cohort 5 to 30 years ${ }^{5}$ to $13.5 \%$ in adolescents (mean age 15.4 years) from the T1D Exchange Registry (T1DX) study, with higher prevalence in those of black/African American descent (17.9\%) and Hispanic/Latino descent $(15.9 \%){ }^{6}$ When a more conservative criteria is used $(\mathrm{BMI}>97$ th percentile), data from the large multicenter German and Austrian database (Diabetes Patienten Verlaufsdokumentation) showed a lower prevalence of obesity of as low as $2.8 \%$ among patients aged $<20$ years old. ${ }^{7}$ In the T1DX and the Prospective Diabetes Follow-up Registry, the BMI $z$ scores in patients aged 2 to 18 years diagnosed with T1D for at least 1 year from Germany, Austria and the United States were greater than the respective countryspecific national data. ${ }^{8}$ However, in the USA population aged 3 to 19 years from the SEARCH for Diabetes in Youth Study, youths with T1D had a higher prevalence of being overweight ( $22.1 \%$ vs $16.1 \%$ ), but not of obesity $(12.6 \%)$, than non-diabetic youths. ${ }^{9}$

When obesity is defined by a BMI $\geq 30 \mathrm{~kg} / \mathrm{m}^{2}$, its prevalence was $8.9 \%$ in patients from Sweden aged $\geq 18$ years old ${ }^{10}$ which increased to $35.9 \%$ in American men between 35 and 67 years $^{11}$ and $37.1 \%$ in one cohort of newly diagnosed T1D between 30 and 75 years from Australia. $^{12}$

\section{What Has Happened in the Previous Decades Regarding the Relationship Between Obesity and Type I Diabetes?}

Overall, obesity rates seem to have stabilized among younger people but have increased over time in adults with T1D. In Australia, a retrospective study that included 1975 children aged $<16$ years at diagnosis of T1D, showed that the prevalence of obesity remained steady (34-35\%) between 1995 and 2009. ${ }^{13}$ Similarly, a US study that examined trends in obesity over 10 years among 507 youths (aged 8-16 years) with T1D found a consistent prevalence rate across time, suggesting a plateau of obesity incidence. ${ }^{14}$ However, when adults with T1D from the Pittsburgh Epidemiology of Diabetes Complications Study were evaluated, the prevalence of obesity increased over time, from $3.4 \%$ at baseline (1986 to 1988 ) to $22.7 \%$ during the final reported time point (2004 to 2007). ${ }^{15}$ Notably, the rise in obesity's prevalence was not due to aging of the cohort and occurred faster than the increase in the general population. ${ }^{15}$ Similarly, in the Epidemiology of Diabetes Interventions and Complications trial, the obesity prevalence in T1D increased from 1\% at baseline (1983 to 1989 ) to $31 \%$ at year 12 (2005), a rate change that was much higher than observed in the general population. ${ }^{16}$ 


\section{Is Obesity a Risk Factor for Developing Diabetes?}

It has been suggested that there is a likely association between higher birthweight, childhood obesity and higher BMI, and subsequent increased risk of childhood-onset T1D. ${ }^{17,18}$ However, it is unclear at what age obesity shows the greatest impact nor the underlying mechanism. A British study in 168 young people presenting with T1D between 1980 and 2002 showed that both pre-onset and post-diagnosis BMI were inversely correlated with age at onset, suggesting that heavier children developed T1D earlier. $^{19}$ Similarly, a systematic review and metaanalysis that included 4 studies that measured BMI prior to the diagnosis of $\mathrm{T} 1 \mathrm{D}$, supported the temporal association between exposure to obesity and the development of T1D. ${ }^{17,20-23}$ Although the studies varied in the definition of obesity, the age at measurement and in sample size, with odds ratios (OR) that ranged from 1.73 to 3.77 , the metanalysis obtained a pooled OR of 2.03 (95\% CI 1.46 2.80). On the other hand, the reversed trend in the incidence of childhood T1D in Sweden, starting in 2000, has been partially attributed to changes in non-genetic risk factors such as the good control of childhood obesity. ${ }^{24}$ Finally, in 91 children with clinical onset of type-1 diabetes at 4-15 years of age, there was increased weight (BMI) gain in the first year of life compared with their 125 healthy siblings. ${ }^{25}$ Remarkably, this early growth was associated at diagnosis with the presence of autoantibodies toward the IA-2 and the tyrosine phosphatase pancreaticcell-like protein, but not with antibodies to glutamic acid decarboxylase. Similarly, in the Finnish population, the risk of type 1 diabetes onset increased 1.19-fold per a $1 \mathrm{~kg} / \mathrm{m}^{2}$ rise in the infancy maximum BMI. ${ }^{26}$

As the combined prevalence of overweight and obesity in the childhood population has accelerated in many developing and developed countries, effective prevention and intervention programs should be a priority of national policy agendas to avoid the continuing increase of T1D in childhood for decades to come. ${ }^{27}$

\section{Mechanisms Underlying the Relation Between Obesity and Type I Diabetes}

Among several possible mechanisms highlighted to explain the association between obesity and subsequent onset of T1D, there appears the classical "accelerator hypothesis". ${ }^{28}$ In this theory, increased body weight boosts the demand for peripheral insulin, imposing more stress on $\beta$ cells and rendering them more antigenic and more vulnerable to autoimmune attack. At the same time, the ectopic lipid deposition in islets acts as an additional trigger of $\beta$ cell apoptosis and the subsequent onset of T1D. Thus, a link between beta cell lipotoxicity and islet inflammation related to cytokine toxicity associated with obesity has been shown in experimental models. ${ }^{29}$ Insulin resistance in T1D may also implicate the transient receptor potential vanilloid-1 (TRPV1+) sensory neurons to promote the local islet inflammation. ${ }^{30}$ In fact, TRPV1 may contribute to obesity and T2D, where sensory innervation of fat may play an analogous role to sensory neurons in pancreatic $\beta$ cells. In addition, adipose tissue is characterized by the production of adipokines which stimulate the generation of reactive oxygen species and proinflammatory molecules, collaborating in the development of a dysfunctional antioxidant system and insulinresistance. ${ }^{31}$ In this context, the increased oxidative stress that is associated with obesity might make the achievement of correct metabolic control in patients with T1D difficult.

The gut microbiome is altered in obesity and should be considered as an important environmental modulator of the susceptibility to diabetes in subjects with obesity. ${ }^{32}$ In fact, both animal and human studies have demonstrated a link between gut microbiota and $\beta$ cell autoimmunity. ${ }^{33}$ However, the underlying mechanisms of how the gut microbiota interacts with host immunity, induce antigenspecific pathogenic T cells, and modulate $\beta$ cell autoimmunity in the initiation of T1D are not yet fully elucidated.

Given that a genetic component is well known to exist in T1D, genomics offers an opportunity to discover new targets for this disease. In this way, the transcription factor 7 like-2 (TCF7L2) loci on chromosome 10, that has often been related with T2D in genome-wide association studies (GWAS), has also been associated with both latent autoimmune diabetes in adults and various presentations of T1D. ${ }^{34}$ However, this genetic overlap between T1D and T2D is still controversial, as Field et al failed to find any evidence for association between TCF7L2 and type 1 diabetes in 6199 white UK type 1 diabetic subjects and 7596 geographically matched white control subjects. $^{35}$ On the other hand, in 830 newly diagnosed autoimmune T1D, TCF7L2 variants were associated with single autoantibodies at diagnosis, higher C-peptides, and lower glucose levels during an oral glucose tolerance test. $^{36}$ 


\section{Obesity, Type I Diabetes Mellitus, and Diabetes Complications}

Some studies have assessed the impact of obesity in the development of chronic complications in patients with T1D, suggesting that individuals with obesity are at an increased risk for macrovascular and some microvascular complications, such as retinopathy. ${ }^{2,4}$ Excess weight gain in patients with T1D is associated with the development of central adiposity, insulin resistance, inflammation and dyslipidemia; all of which are key elements of the metabolic syndrome and T2D and are established risk factors for cardiovascular disease (CVD). ${ }^{37,38}$ In patients with T1D and obesity, the coexistence of these clinical characteristics of T2D, such as insulin resistance and cardiometabolic complications, has been referred to as "double diabetes". ${ }^{39,40}$ (see Figure 1). Regarding this, when the components of the metabolic syndrome were evaluated in 326 individuals with T1D aged between 5 and 34 years, the prevalence of low levels of high-density lipoproteincholesterol was three times higher and hypertension was four times higher among obese individuals compared with normal-weight individuals. ${ }^{5}$ In a similar way, the prevalence of the metabolic syndrome increased from $4.9 \%$ among patients with normal weight to $35.3 \%$ among obese patients. ${ }^{5}$ Moreover, in an observational study in adults with T1D, obesity was associated with the presence and progression of coronary artery calcium, a marker of subclinical atherosclerosis. ${ }^{41}$ Similarly, data from the

\section{TYPE 1 DIABETES}
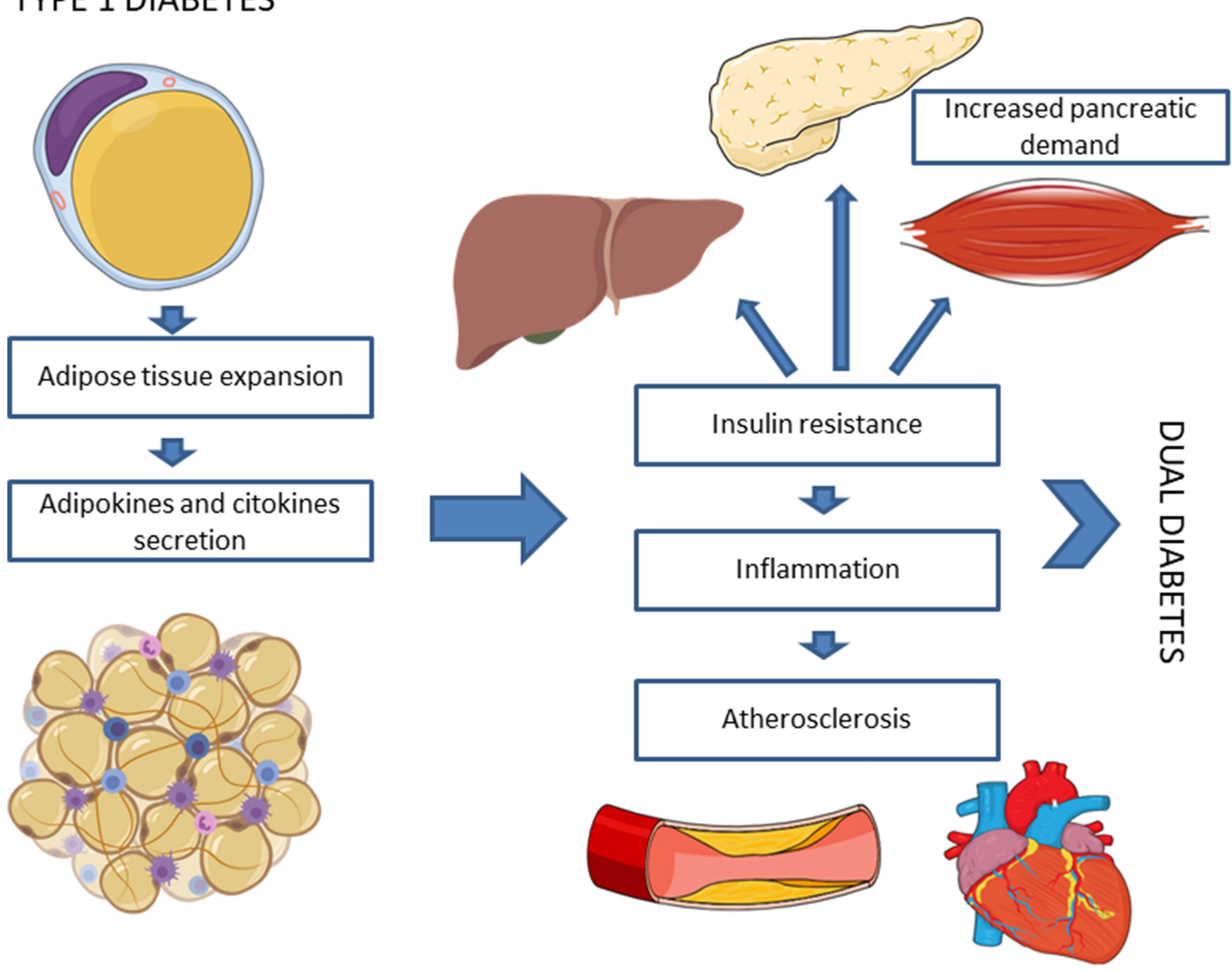

Figure I In patients with type I diabetes adipose tissue deposits produce adipokines and inflammatory cytokines that induce insulin-resistance contributing to the development of cardiometabolic complications. The coexistence of these clinical characteristics of type 2 diabetes in patients with type I diabetes has been referred to as double diabetes. 
DCCT showed that in those patients with T1D with the most excessive weight gain, there were increases in both cardiometabolic risk factors (lipids, blood pressure) and more extensive atherosclerosis. ${ }^{37,38}$ In addition, after year 14 , the cardiovascular events in the intensive insulin therapy group with the most weight gain were significantly higher than the minimal weight gain group $(\mathrm{P}=0.024$; unadjusted hazard ratio $1.99 ; 95 \% \mathrm{CI}, 1.12$ to 3.63 ), with the event rate becoming indistinguishable from the conventional group. ${ }^{37,41}$

Data from 20,985 adults with T1D included in the Swedish National Diabetes Registry showed that obesity was significantly associated with an increased risk for a heart failure hospitalization, with an adjusted Hazard Ratio (HR) of 1.55 and 2.90 for BMI $30-34.9 \mathrm{~kg} / \mathrm{m}^{2}$ and (95\% CI, 1.20 to 1.99 ) and BMI $\geq 35 \mathrm{~kg} / \mathrm{m}^{2}$, respectively. ${ }^{10}$ In a prospective study of 501 Australian adults with $\mathrm{T} 1 \mathrm{D}$, obesity defined as a BMI $>30 \mathrm{~kg} / \mathrm{m}^{2}$ was the main risk factor for cardiovascular disease and retinopathy, although with a similar HbA1c and disease duration compared to non-obese patients. ${ }^{42}$ In the same study, obesity was also associated with albuminuria in women. Similarly, in a cross-sectional study with 176 adults with T1D, BMI appeared to be significantly correlated with retinopathy only in those without previous nephropathy. ${ }^{43}$

Patients with T1D and obesity therefore receive more drugs than their normal-weight counterparts in order to treat the associated cardiometabolic risk factors. This can lead to polypharmacy which is a problematic issue as it exposes patients to adverse drug reactions, drug-drug or drug-disease interactions and is associated with morbidity. $^{44}$

\section{Causes of Increasing Prevalence of Obesity in Type I DM}

Exogenous insulin use and intensive insulin treatment has been considered a key factor promoting weight gain in patients with T1D. ${ }^{2}$ Since the Diabetes Control and Complications Trial (DCCT), multiple daily injections or insulin pump therapy coupled with frequent blood glucose monitoring has become the standard of care of T1D. ${ }^{45}$ Despite the beneficial outcomes in the DCCT, adults receiving intensive insulin therapy gained an average of $5 \mathrm{~kg}$ more than those receiving conventional therapy. ${ }^{46}$ However, studies that have followed cohorts of patients with T1D in the long term have observed that despite doubling the use of intensive insulin therapy after DCCT,
z-BMI and prevalence of overweight and obesity remained stable during a 10-year interval, similar to the general pediatric population. These findings go against intensive insulin therapy being the main reason for the rising prevalence of obesity in patients with T1D. ${ }^{14}$

It is the availability of high-energy density diets and increased portion size, along with a sedentary lifestyle which are the main drivers of obesity development worldwide. $^{47,48}$ The trigger therefore of the increasing prevalence of obesity in T1D is the obesogenic environment. Nevertheless, obesity is a complex multifactorial chronic disease; besides unhealthy habits, other exogenous factors such as the presence of altered eating behavior, eating disorders, short sleep duration, chronic stress and other psychosocial factors are implicated in its etiology. Moreover, current scientific knowledge has shown that other non-modifiable endogenous biological factors such as gut hormone profile, genetic predisposition, epigenetics or intestinal microbiota may also play a role in obesity development. $^{49}$ Different causes of obesity in T1D are illustrated in Figure 2.

Regarding biological factors, gastrointestinal hormones including ghrelin, cholecystokinin, gastric inhibitory peptide (GIP), glucagon-like peptide-1 (GLP-1), oxyntomodulin, amylin, insulin, leptin, pancreatic peptide and pancreatic polypeptide Y (PPY) among others, are key regulators in food intake. However, in T1D, the secretion of insulin, amylin (which favors delaying gastric emptying and inhibits intake) and glucagon are markedly dysregulated. ${ }^{50}$ Apart from the expected loss of secretion of amylin and insulin by $\beta$ cells, $\alpha$ cells are also dysfunctional resulting in a deficient secretion of glucagon in

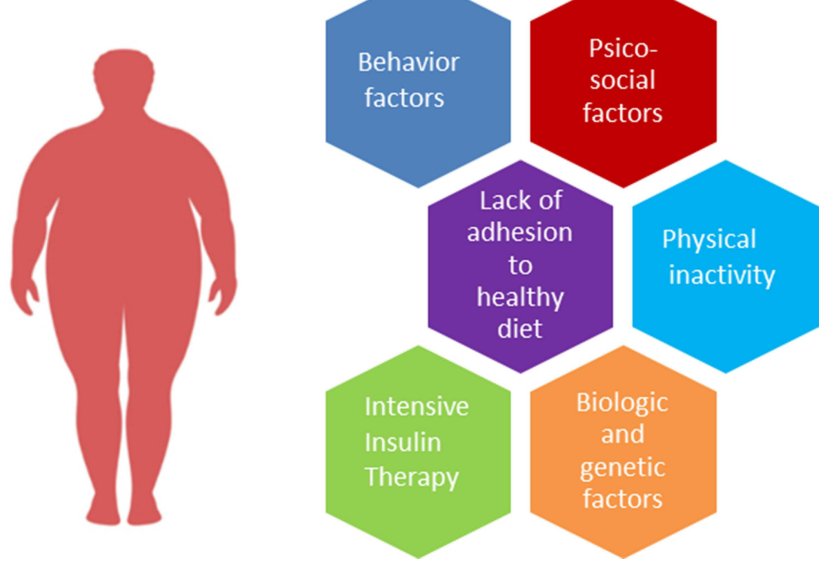

Figure 2 Illustration of the main modifiable and endogenous biological factors implicated in obesity etiology. 
hypoglycemia and lack of glucagon suppression in the postprandial state. ${ }^{51}$ All this inherent hormonal disbalance can potentially contribute to alterations in food intake, thus promoting weight gain.

From what has been explained previously, when treating a patient with obesity and T1D we have to take into account the coexistence of two chronic diseases in which all the above aspects are interrelated and should be carefully addressed. ${ }^{52}$

\section{Treatment of Obesity in TID: Challenges and Opportunities}

The pillars of obesity treatment include a healthy eating plan, scheduled physical activity, and behavioral interventions that should be adapted in case of T1D. Structured lifestyle intervention programs have shown to be more effective in weight loss than a standard course of action in patients with obesity. ${ }^{49}$ Although evidence is scarcer, these structured programs have proven equally beneficial when T1D coexists. ${ }^{53}$ These programs should be executed by a multidisciplinary team that includes endocrinologists, dietitians/nutritionists, nurses, educators, physical activity professionals as well as clinical psychologists. ${ }^{54}$ The participation of a diabetes educator and a close follow-up by an expert team in diabetes is mandatory to adjust carbohydrate intake and to carefully titrate insulin dose to prevent hypoglycemia. Indeed, one of the main barriers to diet interventions in T1D is the occurrence of hypoglycemia and its compensatory overeating. $^{55}$

The administration of short-acting insulin immediately after meals or within 20 minutes from the start of the meal can be useful in some cases to avoid low glucose values. ${ }^{53}$ On the other hand, it is important to assess changes in insulin type to those with a more favorable profile in terms of weight. Multiple trials have shown that patients with diabetes who used insulin detemir as the basal component of intensive insulin therapy, maintained weight neutrality or even had small weight reductions over 1 year in comparison to NPH insulin. ${ }^{56}$ In a recent meta-analysis including patients with $\mathrm{T} 1 \mathrm{D}$ and $\mathrm{T} 2 \mathrm{D}$, those receiving insulin detemir gained less body weight than those given degludec or Glar-100. ${ }^{57}$ Another systematic review concluded there was less weight gain with basal insulin analogues detemir and Glar-300 compared to Glar-100 and degludec but with a low quality of evidence. ${ }^{58}$ Therefore, in the case of obesity and T1D, switching long-acting insulin to either detemir or Glar-300 could be somewhat useful to prevent weight gain.

The incorporation of the new technology of continuous subcutaneous insulin infusion (CSII) in T1D treatment has shown no clinical benefit over multiple daily injections, in terms of weight outcomes in newly diagnosed children and in young patients with T1D, either during the first year of insulinization $^{59}$ or over a 10 -year follow-up. ${ }^{60}$

\section{Diet}

For the management of obesity in T1D lifestyle changes are essential, which must necessarily begin with a dietary modification towards a healthy eating pattern. A high intensity face-to-face dietary intervention program (with more than 14 sessions in 6 months) in the context of a comprehensive lifestyle intervention is the most effective strategy, obtaining average weight losses of $5-10 \% .^{53}$ A variety of diets can lead to weight loss in overweight or obese adults with and without T2D (the Mediterraneandiet, low-carbohydrate, vegetarian or plant-based) $54,61,62$ but to date, there is inadequate research in T1D to support one over another. ${ }^{63}$ Taking into account that the macronutrient composition of a diet has less impact on weight loss than the adherence to it, the proposed diet plan must be adapted to the clinical characteristics and preferences of each patient, and must be planned to facilitate long-term adherence. The presence of a dietitian in the multidisciplinary team is therefore essential. ${ }^{61}$

The main component of any dietary intervention in obesity, independent of the presence of diabetes, is reducing total caloric intake. An energy reduction in the diet of $500-1000 \mathrm{kcal}$ per day or $25-30 \%$ of the daily caloric intake can lead to a weight loss of 0.5 and $1 \mathrm{~kg} / \mathrm{week}$, equivalent to more than $5 \%$ weight loss in an average period of 6 months. The reduction of the size of the consumed portions and/or the energy density of the diet are effective strategies to reduce weight in patients with obesity. Focus should be made in T1D in encouraging consumption of carbohydrates with low glycemic index and high fiber content from vegetables, legumes, fruits, and whole grain and avoid refined carbohydrates, added sugars and highly processed foods. ${ }^{61-63}$.

In our environment, the hypocaloric Mediterranean diet is the one that best represents this balanced and healthy approach that is desired for T1D. The Mediterranean diet is characterized by a high content of vegetables, fruits, legumes, complex starches and food rich in omega-3 fatty acid (fatty fish), omega-6 fatty acid 
(nuts) and monounsaturated fatty acids (olive oil) and promotes low intakes of saturated, trans fatty acids and added sugars. ${ }^{64}$ Moreover, it is associated with a reduction in the risk of numerous diseases including cardiovascular disease, cancer, type 2 diabetes and neurodegenerative diseases. ${ }^{65}$ Even though hypothetically optimal, there is little evidence of Mediterranean diet intervention in T1D. In a trial that randomized patients with T1D and metabolic syndrome to a 6-month non-calorie restricted Mediterranean diet versus a low-fat diet, the effects on waist circumference, anthropometric and metabolic outcomes were similarly favorable with both dietetic approaches. $^{66}$

Current ADA guidelines suggest a flexible approach to carbohydrate intake matched with intensive insulin therapy because there is no ideal macronutrient composition for meal plans. ${ }^{63}$ However, the evidence of low carbohydrate $(<130 \mathrm{~g}$ carbohydrate/day) and ketogenic diets $(<55 \mathrm{~g}$ carbohydrate/day) in T1D deserves special attention. Although it is very popular to lose weight in populations with obesity and T2D, there is limited evidence of their use in T1D as some concerns have been raised mainly regarding the risks of hypoglycemia and DKA. ${ }^{67}$ In this respect, a low carbohydrate diet (LCD) can impair the effect of glucagon in the presence of hypoglycemia due to a reduction in hepatic glycogen stores. In a study performed on individuals with insulin pump-treated T1D, an LCD ( $<50 \mathrm{~g} /$ day $)$ attenuated the glycemic response to a subcutaneous glucagon bolus compared to a high carbohydrate diet. ${ }^{68}$

Only a handful of studies, limited by small sample sizes and mostly non-RCT, have been published comparing the effects of LCD versus higher carbohydrate diets. ${ }^{68-72}$ A systematic review based on them concluded that due to their heterogeneity it was unclear which diet was superior regarding $\mathrm{HbA} 1 \mathrm{c}$ improvement, total daily insulin, incidence of hypoglycemia, or BMI. ${ }^{73}$

Recently, other popular forms of diet plans for weight loss are intermittent fasting, understood as the severe restriction of intake $>60 \%$ for 2-3 days a week or alternate days, or as a limitation of the intake period to 8-10 hours a day or less during most days (time-restricted feeding). In review studies and meta-analysis of the few trials carried out to date, it has not been possible to verify a significantly greater weight loss with these diets compared to conventional low-calorie diets. ${ }^{74,75}$ Additionally, their effectiveness and safety in people with T1D have not yet been conclusively proven and would therefore clearly require adequate training and an adjustment in medication in order to avoid hypoglycemia.

From previously revised data we can conclude that further studies centered on nutrition-based interventions in patients with T1D and obesity are needed. Nevertheless, our recommended dietetic approach to lose weight in T1D would be a hypocaloric diet based on the Mediterranean diet pattern, with $40-50 \%$ of the energy coming from carbohydrates with low glycemic index and high fiber content $(>25-30 \mathrm{~g} / 1000$ $\mathrm{kcal}$ ), $15-25 \%$ from proteins (or $1.2 \mathrm{~g} / \mathrm{kg}$ ideal body weight), and $30-35 \%$ from fat (ensuring a high content in monounsaturated fats and low in trans and saturated fats).

\section{Physical Activity}

The benefits of physical activity on cardiovascular and psychological health are multiple and its promotion is pivotal in obesity and T1D management. ${ }^{76}$ However, patients with T1D engage in less physical activity than those without diabetes and have a tendency to live a sedentary lifestyle that promotes obesity development. ${ }^{77}$ The practice of physical activity in isolation as a treatment for obesity has a modest effect on weight loss. However, when associated with a hypocaloric diet, exercise has been shown to decrease fat mass and visceral adiposity, decrease the loss of lean body mass, and increase insulin sensitivity. In addition, maintaining physical exercise has been shown to be useful in reducing the risk of weight regain. ${ }^{62}$

The goal for children and adolescents with T1D according to $\mathrm{ADA}$ recommendations is $60 \mathrm{~min}$ of moderate to vigorous intensity aerobic activity daily (walking, jogging, dancing, pedaling, etc.), with vigorous muscle-strengthening and bone-strengthening activities at least 3 days per week. ${ }^{63}$ For adults, it is recommended $150 \mathrm{~min}$ or more of moderate to vigorous intensity aerobic activity per week, spread over at least 3 days/week and 2-3 sessions/week of resistance exercise. Shorter durations (minimum $75 \mathrm{~min} /$ week) of vigorous intensity or interval training may be sufficient for younger and more physically fit individuals. The same recommendations are given for people with obesity. ${ }^{62}$

The prescription of physical exercise must be individualized and the participation of physical activity professionals should be considered for a better adaptation to the characteristics and functional capacity of the patient, with the aim of improving adherence. The main barrier to do exercise in T1D is the fear of severe hypoglycemia ${ }^{78}$ that may occur during or up to $24 \mathrm{~h}$ after exercise due to increased insulin sensitivity and delayed replenishment of liver and muscle glycogen following exercise. On the other hand, an 
excessive and/or frequent intake of carbohydrates is not advisable in people with obesity because it promotes weight gain. Therefore, it is important to be educated on strategies to reduce hypoglycemia that can take place during, after and overnight following exercise. After exercise, the decrease of the long-acting insulin doses by $\sim 20-30 \%$, and $50 \%$ of bolus (or in case of insulin pumps the reduction of basal rate by $\sim 10-50 \%$ and $25-75 \%$ of bolus or even its suspension for 1-2 $\mathrm{h}$ during exercise), may lower the risk of hypoglycemia. ${ }^{79}$ Along with frequent blood glucose monitoring, accessible rapid-acting carbohydrates before, during, and after exercise is advisable. For low-to-moderate intensity aerobic activities (30-60 $\mathrm{min}$ ), and if the patient is fasting, the recommendation is $10-15 \mathrm{~g}$ of carbohydrate and after insulin boluses it can reach $0.5-1.0 \mathrm{~g}$ of carbohydrates/ $\mathrm{kg}$ per hour of exercise. ${ }^{63,80}$

The use of new technologies such as accelerometers, smart-watches, and mobile phone applications can contribute to assess and improve the adherence of patients to exercise programs. $^{81}$

\section{Psychological and Behavioral Therapy}

Patients with overweight or obesity are vulnerable to stigma and discrimination in the workplace, at school, in healthcare settings and in society in general leading to negative psychological consequences. Health care providers should avoid stigmatization and weight bias and employ a motivational interview with the patient. $^{82}$

Psychosocial disturbances in obesity and in T1D are frequent and they should be identified and treated appropriately. ${ }^{83,84}$ Some are characteristics of diabetes such as fear of hypoglycemia and diabetes distress, and others are shared by both diseases such as anxiety, depression, lack of support, low self-esteem and the distress of coping with a chronic disease. Eating disorders are also frequent in both entities, with estimated prevalence of $7 \%$ in patients with $\mathrm{T}_{1} \mathrm{D}^{85}$ and reaching $16-50 \%$ in cases of obesity alone according to different studies. ${ }^{86,87}$ In patients with T1D suffering from eating disorders, insulin omission is frequent and is associated with a worse metabolic control, risk of ketoacidosis events and higher rates of diabetes complications. ${ }^{88}$ On clinical suspicion raised by a poor glycemic control and recurrence of hypoglycemic episodes, several questionnaires can be useful to identify eating disorders in T1D such as the Diabetes Eating Problem Survey, Eating Disorder Inventory-3, and modified SCOFF. ${ }^{89,90}$ In a preliminary study, initiation of pump therapy improved disordered eating behaviors probably due to greater flexibility in eating patterns and increased regulation of hunger and satiety. However, evidence is still scarce and further studies are needed to evaluate the impact of CSII insulin pumps on eating problems. ${ }^{91}$

Derived from the above knowledge, psychological assessment and behavioral therapy should be incorporated into the routine clinical management of obesity in T1D and involve clear and reasonable goal setting, self-monitoring of food intake and exercise, an approach to problem solving, development of skills for managing difficulties, stimulus control, stress reduction, education and social support. These behavioral interventions have proven to be beneficial in the context of a structured weight intervention program. ${ }^{53}$

\section{Pharmacological Treatment of Obesity in TID}

Those patients who have insufficient weight loss with diet and exercise are candidates for drug treatment. Current guidelines indicate that pharmacological obesity treatment can be used in patients with $\mathrm{BMI} \geq 30 \mathrm{~kg} / \mathrm{m}^{2}$ or $\mathrm{BMI} \geq 27 \mathrm{~kg}$ / $\mathrm{m}^{2}$ in the presence of complications, as an addition to lifestyle changes. ${ }^{49,54,62}$ Anti-obesity medications approved for long-term use by both the EMA (European Medicines Agency) and FDA (U.S Food and Drug Administration) are Orlistat, Naltrexone-Bupropion and Liraglutide $3.0 \mathrm{mg}$. The Phentermine-Topiramate combination is only FDA approved. ${ }^{49,54,62}$ These treatments have shown that along with weight loss there is an improvement in insulin resistance and metabolic control in T2D (Table 1) but no data are available on their effects on diabetic complications. Although these drugs are not contraindicated in T1D, data about their use in these patients are nonexistent as they have been excluded from the main trials. Despite these limitations, it seems reasonable to assume that obese people with T1D may benefit from these drugs in real life. Not including T1D in pharmacological obesity management clinical trials introduces a bias that leads to a further increase in a discrimination due to the obesity of these patients. Table 1 shows the main results of these studies in patients with T2D as well as in their adverse events and contraindications.

\section{Anti-Obesity Medications}

\section{Orlistat}

Orlistat is a reversible inhibitor of lipases. At the recommended therapeutic dose of $120 \mathrm{mg}$ three times a day, orlistat inhibits dietary fat absorption by approximately $30 \%$. In a meta-analysis of 14 studies, orlistat reduced weight $2.9 \%$ more than placebo. ${ }^{92}$ 
Table I Anti-Obesity Pharmacological Therapy in Randomised Clinical Trials (>I Year of Duration), Including Subjects with Type 2 Diabetes

\begin{tabular}{|c|c|c|c|c|c|c|c|c|c|}
\hline & \multirow[t]{2}{*}{$\begin{array}{l}\text { Duration } \\
\text { (Years) }\end{array}$} & \multirow[t]{2}{*}{$\begin{array}{l}\text { Participants } \\
\text { (n) }\end{array}$} & \multicolumn{2}{|c|}{ Weight Loss } & \multicolumn{2}{|c|}{$\begin{array}{l}\geq \mathbf{5} \% \text { Weight } \\
\text { Loss }\end{array}$} & \multirow[t]{2}{*}{ Dropouts } & \multirow[t]{2}{*}{ Side Effects } & \multirow[t]{2}{*}{ Contraindications } \\
\hline & & & Drug & Placebo & Drug & Placebo & & & \\
\hline $\begin{array}{l}\text { Orlistat }^{92} \\
\text { Meta-analysis }\end{array}$ & $1-4$ & 6196 & $-6.4 \%$ & $-3.5 \%$ & $54 \%$ & $33 \%$ & $\approx 30 \%$ & $\begin{array}{l}\text { Oily spotting, } \\
\text { flatus with } \\
\text { discharge, } \\
\text { diarrhea, fecal } \\
\text { urgency }\end{array}$ & $\begin{array}{l}\text { Chronic malabsorption } \\
\text { syndrome, cholestasis } \\
\text { and oxalate } \\
\text { nephrolithiasis }\end{array}$ \\
\hline $\begin{array}{l}\text { Naltrexone- } \\
\text { Bupropion } \\
\text { COR-I }^{93} \\
\text { COR-2 }^{94} \\
\text { COR-BMOD }^{95} \\
\text { COR-DIABETES }^{96}\end{array}$ & $\begin{array}{l}1 \\
1 \\
1 \\
1\end{array}$ & $\begin{array}{l}1742 \\
1496 \\
793 \\
505\end{array}$ & $\begin{array}{l}-6.1 \% \\
-6.4 \% \\
-9.3 \% \\
-5.0 \%\end{array}$ & $\begin{array}{l}-1.3 \% \\
-1.2 \% \\
-5.1 \% \\
-1.8 \%\end{array}$ & $\begin{array}{l}48.0 \% \\
50.5 \% \\
66.4 \% \\
44.1 \%\end{array}$ & $\begin{array}{l}16.0 \% \\
17.1 \% \\
42.5 \% \\
26.3 \%\end{array}$ & $\begin{array}{l}50 \% \\
46 \% \\
48 \% \\
48 \%\end{array}$ & $\begin{array}{l}\text { Nausea, } \\
\text { constipation, } \\
\text { headache, } \\
\text { vomiting, } \\
\text { dizziness, } \\
\text { insomnia, dry } \\
\text { mouth, and } \\
\text { diarrhea }\end{array}$ & $\begin{array}{l}\text { Uncontrolled } \\
\text { hypertension, seizures, } \\
\text { eating disorders, chronic } \\
\text { opioid use, concurrent } \\
\text { use with monoamine } \\
\text { oxidase inhibitors within } \\
\text { I4 days }\end{array}$ \\
\hline $\begin{array}{l}\text { Phentermine/ } \\
\text { topiramate } \\
\text { CONQUER }^{97} \\
4(7.5 / 46 \mathrm{mg}) \\
(15 / 92 \mathrm{mg}) \\
\text { SEQUEL }^{99} \\
(7.5 / 46 \mathrm{mg}) \\
(15 / 92 \mathrm{mg}) \\
\text { EQUIP }^{98} \\
(15 / 92 \mathrm{mg}) \\
\text { OB-202/DM-230 } \\
\text { Study } \\
\text { Plus CONQ }\end{array}$ & 2 & $\begin{array}{l}2487 \\
498 \\
995 \\
676 \\
227 \\
295\end{array}$ & $\begin{array}{l}-7.8 \% \\
-9.8 \% \\
-9.3 \% \\
-10.5 \%\end{array}$ & $\begin{array}{l}-1.2 \% \\
-1.2 \% \\
-1.8 \% \\
-1.8 \%\end{array}$ & $\begin{array}{l}62 \% \\
70 \% \\
75.2 \% \\
79.3 \%\end{array}$ & $\begin{array}{l}21 \% \\
21 \% \\
30 \% \\
30 \%\end{array}$ & $\begin{array}{l}30.9 \% \\
36.0 \% \\
17.6 \% \\
16.9 \% \\
41.2 \% \\
19.7 \%\end{array}$ & $\begin{array}{l}\text { Paraesthesia, } \\
\text { dizziness, } \\
\text { dysgeusia, } \\
\text { insomnia, } \\
\text { constipation, } \\
\text { and dry mouth }\end{array}$ & $\begin{array}{l}\text { Glaucoma, } \\
\text { hyperthyroidism, } \\
\text { concurrent use with } \\
\text { monoamine oxidase } \\
\text { inhibitors within } 14 \text { days }\end{array}$ \\
\hline $\begin{array}{l}\text { Liraglutide } \\
3.0 \text { mg (SCALE } \\
\text { studies) }^{101} \\
\text { Obesityl } \\
\text { prediabetes }^{102} \\
\text { Maintenance } \\
\text { diabetes }^{104}\end{array}$ & $\begin{array}{l}1 \\
3 \\
1 \\
1\end{array}$ & $\begin{array}{l}3731 \\
2254 \\
422 \\
846\end{array}$ & $\begin{array}{l}-8.0 \% \\
-6.1 \% \\
-6.2 \% \\
-6.0 \%\end{array}$ & $\begin{array}{l}-2.0 \% \\
-1.9 \% \\
-0.2 \% \\
-2.0 \%\end{array}$ & $\begin{array}{l}63.2 \% \\
49.6 \% \\
50.5 \% \\
69.2 \%\end{array}$ & $\begin{array}{l}27.1 \% \\
23.7 \% \\
21.2 \% \\
27.2 \%\end{array}$ & $\begin{array}{l}18 \% \\
47.4 \% \\
25 \% \\
26.7 \%\end{array}$ & $\begin{array}{l}\text { Nausea, } \\
\text { vomiting, } \\
\text { constipation } \\
\text { or diarrhea }\end{array}$ & $\begin{array}{l}\text { Personal or family history } \\
\text { of medullary thyroid } \\
\text { carcinoma or multiple } \\
\text { endocrine neoplasia type } \\
2\end{array}$ \\
\hline
\end{tabular}

Notes: Subjects with diabetes were included in specific clinical trials (COR-DIABETES, SCALE Diabetes). For phentermine-topiramate, sub-studies were used that included patients with T2D, such as OB-202/DM-230 and a sample from the CONQUER study.

Abbreviations: COR, Contrave Obesity Research; BMOD, behaviour modification; SCALE, Satiety and Clinical Adiposity — Liraglutide Evidence.

\section{Naltrexone-Bupropion (NB)}

Bupropion is an inhibitor of the reuptake of dopamine and norepinephrine and is involved in the regulation of appetite (anorectic action) and in the hedonic reward circuits. Naltrexone is a $\mu$-opioid inhibitor. In the COR (Contrave Obesity Research) studies, ${ }^{93-96}$ NaltrexoneBupropion sustained-release (SR) at a dose of $32 /$ $360 \mathrm{mg}$ reduced weight $4.5 \%$ more than placebo (Table 1).

\section{Phentermine-Topiramate}

Phentermine has been used for the treatment of obesity since 1955, and together with the antiepileptic topiramate, this drug combination exerts an anorexigenic action by acting on the GABA and glutamate receptors. In the different randomized double-blind studies (EQUIP, CONQUER and SEQUEL), ${ }^{97-100}$ the percentages of total weight loss have been, on average: low doses $-5.1 \%$, medium dose $-7.1 \%$ and high doses $-10.9 \%$ (Table 1 ). 


\section{Liraglutide $3.0 \mathrm{mg}$}

Liraglutide is an analog of the incretin GLP-1 (Glucagon Like Peptide-1) and is well known for its efficacy and safety in the treatment of T2D at doses of 1.2-1.8 mg/ day. However, the higher dose of $3.0 \mathrm{mg} /$ day is used for obesity treatment.

Among the four pivotal SCALE studies (Satiety and Clinical Adiposity - Liraglutide Evidence), ${ }^{101-104}$ the study concerning obesity with/without prediabetes, which included 3731 patients, showed a total weight loss after 56 weeks of treatment of $-8 \%$ compared to $-2.6 \%$ with placebo. A lower decrease was observed in the SCALEdiabetes study of $-6.0 \%$. Liraglutide's safety and efficacy have been verified for the treatment of adolescents with obesity $^{105}$ (pending approval by regulatory agencies) and it is the anti-obesity drug of choice according to some societies. $^{62}$

\section{Other GLPI Agonists (Semaglutide, Dulaglutide)}

These are long-acting GLP1 analogs approved for use in T2D to improve glycemic control which also exert an additional action on body weight. In a head-to-head study, weekly administered semaglutide $1 \mathrm{mg}$ achieved a weight reduction of $-6.5 \mathrm{~kg}$ compared to $3.0 \mathrm{~kg}$ with dulaglutide $1.5 \mathrm{mg}$. ${ }^{106}$ However, neither treatment was intended to treat obesity.

We have preliminary data that show that obese patients with T2D treated with high-dose Semaglutide $2.4 \mathrm{mg}$ can achieve a reduction of approximately $-9 \cdot 6 \%$ and $-15 \%$ of starting weight in patients with and without diabetes, respectively. ${ }^{107,108}$ Of note, one-third of participants in this last study achieved $20 \%$ of weight loss similar to that obtained with sleeve gastrectomy (SG). The development of new drugs in the future for weight and glycemic control will be based on the combination of drugs like tirzepatide (dulaglutide plus a GIP analog), and combinations of GLP1, GIP, Glucagon coagonists/triagonists, combinations of Semaglutide and Pramlintide analog (Cagrilintide) and the YY peptide agonists. ${ }^{109}$

The authors believe that for those patients unable to achieve a significant and sustained weight loss with lifestyle interventions, the addition of approved anti-obesity drugs and the use of novel molecules derived from gastrointestinal peptides in the near future, will be very useful for weight management in T1D patients, as some approach bariatric surgery (BS) results. As a growing problem worldwide, T1D with obesity should be included in weight loss clinical trials.
Oral Glucose-Lowering Drugs as Adjuncts to Insulin Treatment in TID

A number of oral glucose-lowering drugs used in T2D treatment have been explored as adjuncts to insulin treatment in T1D in the search of improving metabolic control and body weight. Results of the most relevant trials are listed in Table 2.

\section{Metformin}

Metformin is the first-line treatment for T2D. It decreases hepatic glucose production, increases insulin sensitivity and decreases glucose absorption. ${ }^{110}$ Some clinical trials with limited number of participants with T1D have evaluated the effects of metformin added to insulin compared to placebo and have demonstrated a decrease with respect to placebo in insulin dose $(-5.7$ to $-8.8 \mathrm{UI} / \mathrm{d})$ and in weight $(-1.74$ to $-3.8 \mathrm{~kg})$, but no effect on $\mathrm{HbA}_{1 \mathrm{c}} \cdot{ }^{111,112}$ The REMOVAL trial randomized 428 patients with T1D to metformin or placebo and measured the progression of common carotid artery intima-media-thickness (cIMT) as a marker of atherosclerosis. ${ }^{115}$ Body weight was reduced $(-1.17 \mathrm{~kg}, 95 \%$ CI 1.66 to -0.9$)$ but there was no reduction in $\mathrm{HbA}_{1 \mathrm{c}}$, insulin requirements, progression of mean cIMT and no increase in hypoglycemia compared to placebo.

\section{Dipeptidyl Peptidase IV Inhibitors (DPP-IV Inhibitors)}

The DPP-IV inhibitors enhance levels of endogenous glucagon-like peptide 1 (GLP1) by blocking its metabolism by the enzyme DPP-IV. This increase of GLP1 levels, leads to a decrease in glucagon and an increase in insulin secretion. T1D patients experience a paradoxical increase in glucagon, which correlates with postprandial glucose levels. ${ }^{114}$ Sitagliptin has been evaluated and compared to placebo in a limited number of studies in patients with $\mathrm{T} 1 \mathrm{D},{ }^{115,116}$ none observing significant effects on weight.

\section{Glucagon Like Peptide I Analogs (GLPIa)}

Of the six available GLP1a only two have been evaluated in patients with T1D: Exenatide and Liraglutide.

Exenatide: There are few studies evaluating exenatide in patients with T1D, all methodologically heterogeneous and with a limited number of patients. The studies demonstrate a decrease in insulin requirements, ${ }^{117-119}$ but only a small number of them show a significant decrease in $\mathrm{HbA}_{1 \mathrm{c}}{ }^{117,118}$ and in weight loss. ${ }^{117,119}$

Liraglutide: The Lira-1 trial showed no differences in $\mathrm{HbA}_{1 \mathrm{c}}$, but there were significant differences in weight 
Table 2 Studies Analysing the Effects of Oral Glucose-Lowering Drugs as Adjuncts to Insulin Treatment in TID

\begin{tabular}{|c|c|c|c|c|c|c|}
\hline & & $\mathbf{n}$ & $\begin{array}{l}\text { Duration } \\
\text { (Weeks) }\end{array}$ & $\begin{array}{l}\text { Change in } \\
\text { HbA }_{\text {Ic }}(\%)\end{array}$ & $\begin{array}{l}\text { Change in } \\
\text { Weight (kg) }\end{array}$ & $\begin{array}{l}\text { Change in Insulin } \\
\text { Dose }\end{array}$ \\
\hline \multicolumn{7}{|l|}{ Biguanides } \\
\hline REMOVAL $^{1 / 3}$ & Metformin $1000 \mathrm{mg}$ & 428 & 156 & $-0.13^{* *}$ & $-1.17^{* *}$ & $-0.05 \mathrm{lU} / \mathrm{kg} / \mathrm{d}$ \\
\hline \multicolumn{7}{|l|}{ GLPIa } \\
\hline Lira-I ${ }^{120}$ & Liraglutide $1.8 \mathrm{mg}$ & 100 & 24 & -0.2 & $-6.80 *$ & $-0.1 \mathrm{lU} / \mathrm{kg} / \mathrm{d}$ \\
\hline ADJUNCT ONE & $\begin{array}{l}\text { Liraglutide } 1.8 \mathrm{mg} \\
\text { Liraglutide } 1.2 \mathrm{mg} \\
\text { Liraglutide } 0.6 \mathrm{mg}\end{array}$ & 1398 & 52 & $\begin{array}{l}-0.2 * * \\
-0.15 * \\
-0.09 *\end{array}$ & $\begin{array}{l}-4.90 * * \\
-3.55 * * \\
-2.19 * *\end{array}$ & $\begin{array}{l}-5 \% *(\Delta \mathrm{BL}) \\
-2 \%(\Delta \mathrm{BL}) \\
+4 \%(\Delta \mathrm{BL})\end{array}$ \\
\hline ADJUNCT TWO ${ }^{122}$ & $\begin{array}{l}\text { Liraglutide } 1.8 \mathrm{mg} \\
\text { Liraglutide } 1.2 \mathrm{mg} \\
\text { Liraglutide } 0.6 \mathrm{mg}\end{array}$ & 853 & 26 & $\begin{array}{l}-0.35 * * \\
-0.23 * * \\
-0.24 * *\end{array}$ & $\begin{array}{l}-5.10 * * \\
-4.00 * * \\
-2.50 * *\end{array}$ & $\begin{array}{l}\text { Ratio } 0.90 * * \\
\text { Ratio } 0.93 * * \\
\text { Ratio } 0.95 * *\end{array}$ \\
\hline \multicolumn{7}{|l|}{ iSGLT2 } \\
\hline DEPICT-I ${ }^{124}$ & $\begin{array}{l}\text { Dapagliflozin } 10 \mathrm{mg} \\
\text { Dapagliflozin } 5 \mathrm{mg}\end{array}$ & 833 & 52 & $\begin{array}{l}-0.36 * *(\Delta \mathrm{BL}) \\
-0.33^{* *}(\Delta \mathrm{BL})\end{array}$ & $\begin{array}{l}-3.90 * * \\
-2.56 * *\end{array}$ & $\begin{array}{l}N R \\
N R\end{array}$ \\
\hline DEPICT-2 ${ }^{125}$ & $\begin{array}{l}\text { Dapagliflozin } 10 \mathrm{mg} \\
\text { Dapagliflozin } 5 \mathrm{mg}\end{array}$ & 815 & 24 & $\begin{array}{l}-0.42^{* *} \\
-0.37^{* *}\end{array}$ & $\begin{array}{l}-3.74 \%^{\dagger} \\
-3.21 \%^{\dagger}\end{array}$ & $\begin{array}{l}-16.71 \% \\
-11.19 \%\end{array}$ \\
\hline EASE-I ${ }^{126}$ & $\begin{array}{l}\text { Empagliflozin } 25 \mathrm{mg} \\
\text { Empagliflozin } 10 \mathrm{mg} \\
\text { Empagliflozin } 2.5 \mathrm{mg}\end{array}$ & 75 & 4 & $\begin{array}{l}-0.53 * \\
-0.38 * * \\
-0.49 * *\end{array}$ & $\begin{array}{l}-1.90 * * \\
-1.80 * * \\
-1.50 * *\end{array}$ & $\begin{array}{l}-0.07 \mathrm{IU} / \mathrm{kg} / \mathrm{d}^{*} \\
-0.09 \mathrm{IU} / \mathrm{kg} / \mathrm{d} * \\
-0.08 \mathrm{IU} / \mathrm{kg} / \mathrm{d} *\end{array}$ \\
\hline EASE- $2^{127}$ & $\begin{array}{l}\text { Empagliflozin } 25 \mathrm{mg} \\
\text { Empagliflozin } 10 \mathrm{mg}\end{array}$ & 730 & 52 & $\begin{array}{l}-0.45 * * * \\
-0.39 * * *\end{array}$ & $\begin{array}{l}-3.60 * * * \\
-3.20 * * *\end{array}$ & $\begin{array}{l}-12.9 \% * * * \\
-12.0 \% * * *\end{array}$ \\
\hline EASE-3 ${ }^{127}$ & $\begin{array}{l}\text { Empagliflozin } 25 \mathrm{mg} \\
\text { Empagliflozin } 10 \mathrm{mg} \\
\text { Empagliflozin } 2.5 \mathrm{mg}\end{array}$ & 977 & 26 & $\begin{array}{l}-0.52 * * * \\
-0.45 * * * \\
-0.28 * * *\end{array}$ & $\begin{array}{l}-3.40 * * * \\
-3.00 * * * \\
-1.80 * * *\end{array}$ & $\begin{array}{l}-12.6 \% * * * \\
-9.5 \% * * * \\
-6.4 \% * * *\end{array}$ \\
\hline InTandem I ${ }^{128}$ & $\begin{array}{l}\text { Sotagliflozin } 400 \mathrm{mg} \\
\text { Sotagliflozin } 200 \mathrm{mg}\end{array}$ & 793 & 52 & $\begin{array}{l}-0.31 * * \\
-0.25^{* *}\end{array}$ & $\begin{array}{l}-4.34 * * \\
-3.14 * *\end{array}$ & $\begin{array}{l}-12.64 \% * * \\
-8.02 * *\end{array}$ \\
\hline InTandem I ${ }^{129}$ & $\begin{array}{l}\text { Sotagliflozin } 400 \mathrm{mg} \\
\text { Sotagliflozin } 200 \mathrm{mg}\end{array}$ & 782 & 52 & $\begin{array}{l}-0.32 \% * \\
-0.21 \% *\end{array}$ & $\begin{array}{l}-2.18 * * \\
-1.98 * *\end{array}$ & $\begin{array}{l}-8.17 \% * * \\
-6.26 \% *\end{array}$ \\
\hline InTandem I 130 & Sotagliflozin $400 \mathrm{mg}$ & 1402 & 24 & $-0.46 * *$ & $-2.98^{* *}$ & $-5.3 \mathrm{UI} / \mathrm{d} * *$ \\
\hline \multicolumn{7}{|l|}{ Amylin mimetics } \\
\hline $\begin{array}{l}\text { Whitehouse et al } \\
\text { Edelman et } \mathrm{al}^{134} \\
\text { Ratner et } \mathrm{al}^{135}\end{array}$ & $\begin{array}{l}\text { Pramlintide } 30 \mu \mathrm{g} \text { or } 60 \mu \mathrm{g} \\
\text { Pramlintide } 30 \mu \mathrm{g} \text { or } 60 \mu \mathrm{g} \\
\text { Pramlintide } 60 \mu \mathrm{g} \text { or } 90 \mu \mathrm{g}\end{array}$ & $\begin{array}{l}480 \\
296 \\
651\end{array}$ & $\begin{array}{l}52 \\
29 \\
52\end{array}$ & $\begin{array}{l}-0.39 * * \\
-0.19 \\
-0.29 * *\end{array}$ & $\begin{array}{l}\mathrm{NR} \\
-\mathrm{I} .3^{* * *}(\Delta \mathrm{BL}) \\
\mathrm{NR}\end{array}$ & $\begin{array}{l}+2.3 \% *(\Delta \mathrm{BL}) \\
-12 \%(\Delta \mathrm{BL}) \\
\mathrm{NR}\end{array}$ \\
\hline
\end{tabular}

Notes: ${ }^{\dagger}$ Mean percent change. ${ }^{*} p<0.05$. $* * p<0.001$. $* * * p<0.0001$.

Abbreviations: $\triangle \mathrm{BL}$, change from baseline; $\mathrm{NR}$, not reported.

loss $(-6.8 \mathrm{~kg})$ and in insulin dose (5.8 UI of bolus/day) in the group of patients with T1D treated with liraglutide $1.8 \mathrm{mg} / \mathrm{d}$ with respect to the placebo group. In the liraglutide group, the perceived frequency of hypoglycemia was lower and the most frequent adverse events were gastrointestinal effects. ${ }^{120}$
The two trials with the largest number of patients at present (ADJUNCT ONE and ADJUNT TWO) have reported similar results with respect to a significant weight loss (from -4.1 to $-5.1 \mathrm{~kg}$ ) and a reduction in insulin dose in the liraglutide group, but also a decrease in $\mathrm{HbA}_{1 \mathrm{c}}$ (from $0.2 \%$ to $0.35 \%) .{ }^{121,122}$ The gastrointestinal disorders, 
symptomatic hypoglycemia and hyperglycemia with ketosis, were more frequent in the liraglutide groups.

\section{Sodium-Glucose Cotransporter Inhibitors}

SGLT2 is located in the renal proximal tubule and favors glucose reabsorption and SGLT1 promotes glucose absorption in the small intestine. Inhibition of these transporters by SGLT2 and SGLT1 inhibitors leads to a decrease in glucose reabsorption in the kidney and the small intestine, respectively. Moreover, patients with diabetes mellitus present an overexpression of SGLT2. ${ }^{123}$ SGLT2 inhibitors and dual (SGLT2 and SGLT1) inhibitors have been evaluated in patients with T1D.

Dapagliflozin: The DEPICT-1 and DEPICT-2 trials randomized to receive dapagliflozin $5 \mathrm{mg}$, dapagliflozin $10 \mathrm{mg}$ or placebo. ${ }^{124,125}$ In both trials, patients in the groups of dapagliflozin presented a significant decrease in $\mathrm{HbA}_{1 \mathrm{c}}$ compared to placebo (from $-0.33 \%$ to $-0.37 \%$ with dapagliflozin $5 \mathrm{mg}$ and from $-0.36 \%$ to $-0.42 \%$ with dapagliflozin $10 \mathrm{mg}$ ), in insulin dose and in body weight (the mean percentage change vs placebo ranged from $-2.95 \%$ to $-4.54 \%$ ). There were no differences in the rates of hypoglycemia, but incidence of DKA was higher in the treatment groups $(2.6 \%$ to $4 \%$ with dapagliflozin $5 \mathrm{mg}, 2.2 \%$ to $3.4 \%$ with dapagliflozin $10 \mathrm{mg}$ and $0 \%$ to $1.9 \%$ with placebo).

Empagliflozin: The EASE-1 trial $^{126}$ randomized patients to receive empagliflozin $10 \mathrm{mg}$, empagliflozin $25 \mathrm{mg}$ and placebo and the EASE-2 and EASE-3 trials $^{127}$ randomized patients to empagliflozin $2.5 \mathrm{mg}$, $10 \mathrm{mg}, 25 \mathrm{mg}$ or placebo. All trials showed a significant decrease in $\mathrm{HbA}_{1 \mathrm{c}}$ with all doses of empagliflozin vs placebo (from $-0.28 \%$ to -0.53 ). Patients in the treatment groups also experienced a higher reduction in weight (from $-1.5 \mathrm{~kg}$ to $-3.6 \mathrm{~kg}$ ) and in insulin dose. While in the EASE-1 there were no differences in the rate of DKA, in the EASE- 2 and $3^{127}$ trials there were higher rates of DKA in the groups of patients with the higher doses of empagliflozin (10 mg and $25 \mathrm{mg}$ ): $0.8 \%$ with empagliflozin $5 \mathrm{mg}, 4.3 \%$ with empagliflozin $10 \mathrm{mg}, 3.3 \%$ with empagliflozin $25 \mathrm{mg}$ and $1.2 \%$ with placebo.

Sotagliflozin: The program inTandem has evaluated the efficacy and safety of the dual blockade of SGLT1 and SGLT2 by sotagliflozin in T1D. ${ }^{128-130}$ The three trials showed a reduction in $\mathrm{HbA}_{1 \mathrm{c}}$ in the groups of patients treated with sotagliflozin (from $-0.21 \%$ to $-0.46 \%$ ), in weight (from -1.98 to $-4.34 \mathrm{~kg}$ ) and in insulin dose. The frequency of documented hypoglycemia was lower and gastrointestinal events and DKA were more frequent in patients treated with sotagliflozin. With respect to DKA, $3.4 \%$ of patients with sotagliflozin $200 \mathrm{mg}$ presented DKA, $4.2 \%$ with sotagliflozin $400 \mathrm{mg}$ and $0.4 \%$ with placebo.

\section{Amylin Mimetics}

Pramlintide: Pramlintide is a hormone co-secreted with insulin in the postprandial period by $\beta$ cells in response to nutrient stimuli. It modulates glucose absorption, delays gastric emptying and suppresses glucagon secretion. ${ }^{131}$ It is deficient in patients with T1D. ${ }^{132}$ Pramlintide is an amylin analogue, administered subcutaneously in addition to prandial insulin, approved in the USA for the clinical use in T1D and T2D. Pramlintide has been evaluated adjunct to intensive insulin therapy in T1D and trials have shown significant reductions in $\mathrm{HbA}_{1 \mathrm{c}}$ (from $-0.19 \%$ to $-0.39 \%$ compared to placebo), in weight and in insulin doses. ${ }^{133-135}$ Hypoglycemia and gastrointestinal adverse events were more frequent in patients treated with Pramlintide.

Of all these evaluated treatments, in addition to pramlintide, which has been approved in the USA for T1D since 2005, dapagliflozin $5 \mathrm{mg}$ was approved in Europe in 2019 for the use in patients with T1D and BMI $\geq 27 \mathrm{~kg} /$ $\mathrm{m}^{2}$ when insulin alone does not provide an adequate glycemic control despite optimal insulin treatment.

\section{Natural Product Supplementation}

Numerous plants, their extracts and isolated components are under investigation for their possible beneficial effects on body weight. Phytochemicals are plant organic compounds without nutritional effect but with bioactivity, such as carotenoids, polyphenols, flavonoids, alkaloids, tannins, steroids, etc., with a large number of phytoconstituents such as genistein, capsaicin, catechins, ephedrine or caffeine. They are potential sources of new drugs due to their biological activity on metabolic pathways involved in the regulation of intake and energy balance. In human studies, the effect of most of them on body weight is supported by low-quality evidence and only some (green tea, white kidney bean, caffeine, bitter orange, diacylglycerol, resveratrol, grapefruit, chromium) have moderate-quality evidence. However, none is capable of inducing a clinically relevant weight loss, with the most effective ones (green tea) leading to a $2 \mathrm{~kg}$ reduction. ${ }^{136,137}$ Therefore, for the time being, these natural products lack adequate clinical 
investigations and scientific validation to be recommended for obesity therapy.

\section{Bariatric Surgery in TID with Severe Obesity}

In patients with T1D and BMI above or equal to $35 \mathrm{~kg} / \mathrm{m}^{2}$ with associated comorbidities or BMI above or equal to $40 \mathrm{~kg} / \mathrm{m}^{2}$, BS can be a treatment option as supported by IFSO since $2016 .{ }^{138}$ However, contrary to firm benefits of BS in T2D, little is known of its outcomes and risks in populations with T1D. ${ }^{139}$ Therefore, ADA guidelines state that larger and longer studies will be required in order to establish the role of metabolic surgery in such patients. ${ }^{61}$

\section{Pathophysiology}

Patients with T1D have a reduced endogenous insulin secretion, but body weight loss can decrease insulin resistance in hepatic and peripheral tissues and may improve hepatic insulin sensitivity leading to a reduction in insulin requirements. A role of gastrointestinal hormones in metabolic improvement has also been suggested in animal studies. ${ }^{140}$ In this regard, a preliminary study in which one woman with T1D who underwent RYGB reported an increase in the incretin hormones GLP-1, PYY, and GIP after a mixed meal test. ${ }^{141}$ However, other authors were not able to correlate GLP-1 nor glucagon concentrations to changes in glycemic control and insulin requirements. ${ }^{142}$

\section{Outcomes of BS in Patients with TID}

The results of obesity surgery in patients with T1D have only been described until recently in case reports and small series, ${ }^{141-163}$ most with a short follow-up that have given place to several systematic reviews. ${ }^{164-168}$ The main results are summarized in Table 3. Overall, they have shown a significant reduction in body weight and weightadjusted insulin requirements and an improvement in other cardiovascular risk factors (mainly hypertension, dyslipidemia and obstructive sleep apnea). However, only modest and transient benefits on glycemic control have been found, mainly occurring within the first year after bariatric surgery (see Table 3). Our group published the results of a cohort of 32 patients with T1D undergoing BS with a mean follow up of 4.6 years and observed that $\mathrm{HbA}_{1 \mathrm{c}}$ was reduced $0.6 \%$ during the first year, but in the long term, it returned to baseline values. ${ }^{163}$ Nonetheless, a sustained reduction of $51 \%$ in total daily insulin dose, and a decrease in about $50 \%$ of patients with hypertension, dyslipidemia and obstructive sleep apnea was observed.

\section{Safety of BS in Patients with TID}

Besides the improvement of insulin sensitivity after weight loss that requires an appropriate reduction in exogenous insulin dose, the change in glucose kinetics and nutrient intake and absorption may favor hypoglycemic events. Regarding this, food intolerance and vomiting after bariatric surgery and the mismatch between insulin peak after subcutaneous administration, and the higher and earlier postprandial glucose excursion caused by the rapid delivery of carbohydrates to the jejunum promotes hypoglycemia. Thus, this risk would be expected to be greater after mixed and malabsorptive techniques. ${ }^{169}$ However, it is still unknown if the type of surgical technique has a real impact on hypoglycemic events and which one would be the appropriate choice in this context. In our retrospective non-randomized series, $9.3 \%$ of patients had a serious hypoglycemic event, but their frequency did not differ between those surgeries bypassing the duodenum (Roux-en-Y gastric bypass (RYGB) and duodenal switch) and with restrictive ones (SG). ${ }^{163}$ Recently, Höskuldsdóttir et al have published data from a register-based nationwide Swedish cohort including 387 individuals with T1D who had undergone RYGB that were compared to 387 age/BMI/sex and diabetes duration matched control patients. ${ }^{170}$ In this large bariatric population, there was a numeric but not statistically significant difference in hypoglycemic events leading to coma (HR 1.57; $\mathrm{P}=0.205$ ).

DKA is a life-threatening complication that ranges from 6.2 up to $25 \%$ in a series of patients with T1D undergoing BS. ${ }^{163,171}$ In the nationwide Swedish cohort, a higher risk for serious hyperglycemic events (HR 1.99) was found after RYGB surgery compared to controls. ${ }^{170}$ Poor peri-operative glycemic control along with omission or non-compliance with prescribed insulin doses was associated with DKA.

Of note, in the Swedish study a significantly increased risk for alcohol and substance abuse was found after surgery (HR 3.71), as has also been reported in other bariatric series. ${ }^{172}$

\section{Effects of BS on Diabetic Complications}

In preliminary case reports, anecdotical microalbuminuria regression to normoalbuminuria ${ }^{153,163}$ and inconsistent results regarding retinopathy have been described. ${ }^{153}$ In the Swedish cohort study, no difference was found regarding the risk of kidney disease or leg amputation after RYGB compared to controls. ${ }^{170}$ A lower risk for cardiovascular disease 
Table 3 Studies Analyzing the Effects of Bariatric Surgery in Patients with TID

\begin{tabular}{|c|c|c|c|c|c|c|c|}
\hline Study & $\mathbf{n}$ & Type of Surgery & $\begin{array}{l}\text { Follow- } \\
\text { Up }\end{array}$ & $\begin{array}{l}\text { Mean } \\
\text { Decrease } \\
\text { in BMI }\end{array}$ & $\begin{array}{l}\text { Mean } \\
\text { Reduction in } \\
\text { Insulin UI/kg }\end{array}$ & $\begin{array}{l}\text { Mean } \\
\text { Changes in } \\
\text { HbA Ic (\%) }\end{array}$ & $\begin{array}{l}\text { Improvement } \\
\text { in CVRF }\end{array}$ \\
\hline Czupryniak et al ${ }^{144} 2010$ & 3 & RYGB $(n=3)$ & 6.3 years & 8.7 & 0.23 & $\downarrow 3$ & BP, dyslipidemia \\
\hline Mendez et al ${ }^{145} 2010$ & 3 & RYGB $(n=3)$ & lyear & 16.5 & 0.20 & $\uparrow 0.07$ & \\
\hline Garcia-Caballero et al $2013^{157}$ & 5 & SAGB $(n=5)$ & $19 m$ & 7 & $47 \mathrm{UI} / \mathrm{d}$ & $\downarrow 1.6$ & BP, dyslipidemia \\
\hline Raab et al $2013^{148}$ & 6 & $\begin{array}{l}\text { RYGB }(n=2) ; S G(n=1) \\
\operatorname{BPD}(n=3)\end{array}$ & I year & 13.8 & 0.57 & $\downarrow 1.2$ & \\
\hline Chuang et al $2013^{147}$ & 2 & $\operatorname{RYGB}(n=1) ; S G(n=1)$ & $20 \mathrm{~m}$ & 18.1 & $\uparrow 0.05$ & $\uparrow 1.95$ & BP, dyslipidemia \\
\hline $\begin{array}{l}\text { Fuertes-Zamorano et al } \\
2013^{146}\end{array}$ & 2 & SADI-S $(n=2)$ & 4.5 years & 23.0 & 0.26 & $\downarrow 0.85$ & Dyslipidemia \\
\hline Reyes Garcia et al, $2013^{158}$ & I & RYGB $(n=1)$ & $10 \mathrm{~m}$ & 14.6 & $88 \mathrm{UI}$ & $\downarrow 1.3$ & \\
\hline Blanco et al $2014^{142}$ & 7 & RYGB $(n=7)$ & 2 years & 12.1 & $\uparrow 0.01$ & $\downarrow 0.1 \mathrm{NS}$ & - \\
\hline Brethauer et al $2014^{150}$ & 10 & $\begin{array}{l}\text { RYGB }(n=7) ; S G(n=1), \\
\text { GB }(n=2)\end{array}$ & 3years & II.I & 0.34 & $\downarrow 1.1$ & BP, dyslipidemia \\
\hline Tang et al $2014^{151}$ & 6 & $\begin{array}{l}\text { RYGB }(n=1), \text { SG }(n=2), \\
\text { GB }(n=3)\end{array}$ & $16 \mathrm{~m}$ & 11.4 & NR & $\uparrow 0.1 \mathrm{NS}$ & - \\
\hline Lanno et al $2014^{152}$ & 22 & RYGB $(n=16) ;$ SG $(n=6)$ & $37 \mathrm{~m}$ & 8.7 & 0.3 & $\downarrow 0.2 \mathrm{NS}$ & - \\
\hline Middelbeek et al $2015^{153}$ & 10 & RYGB (I0) & 5years & 9.7 & 0.05 & $\uparrow 1.7$ & Increase in HDL \\
\hline Maraka et al $2015^{154}$ & 10 & RYGB $(n=9), S G(n=1)$ & 2 years & 13.1 & NR & $\downarrow 0.4$ NS & Dyslipidemia \\
\hline Robert et al $2015^{155}$ & 10 & BPD $(n=7), S G(n=3)$ & 4.5years & 16.5 & 0.7 & $\downarrow 0.4 \mathrm{NS}$ & BP, dyslipidemia \\
\hline Rottenstreich et al $2015^{160}$ & 13 & RYGB $(n=)$ SG $(n=10)$ & 2 years & 9.8 & 0.19 & $\downarrow 0.8 \mathrm{NS}$ & BP \\
\hline Vilarrasa et al $2017^{163}$ & 32 & $\begin{array}{l}\text { RYGB }(n=11) ; S G(n=15), \\
\text { DS }(n=6)\end{array}$ & 4.6 years & 9.0 & 0.3 & $\uparrow 0.2 \mathrm{NS}$ & $\begin{array}{l}\text { BP, dyslipidemia, } \\
\text { OSA }\end{array}$ \\
\hline Faucher et al $2016^{161}$ & 13 & RYGB (n=6); SG (7) & lyear & 11.5 & 0.33 & $\downarrow 0.7$ & \\
\hline Moreno-Fdez et al $2016^{159}$ & 6 & RYGB $(n=3), S G(n=3)$ & 4.5 years & 14.2 & 0.10 & $\downarrow 0.6 \mathrm{NS}$ & Triglycerides \\
\hline Al Sabah et al $2017^{162}$ & 10 & $S G(n=10)$ & 4 years & 10.5 & 0.46 & $\downarrow 0.3 \mathrm{NS}$ & \\
\hline Landau et al $2019^{156}$ & 26 & $\begin{array}{l}\text { RYGB }(n=10) ; \text { SG }(n=5) \text {; } \\
\text { GB }(n=8)\end{array}$ & 3.5 years & 9.3 & NR & $\uparrow 0.04 \mathrm{NS}$ & $\mathrm{BP}$, increase HDL \\
\hline Hoskuldsdóttir et al $2020^{170}$ & 387 & RYGB $(n=387)$ & 9 years & 12 & NR & $\downarrow 0.8$ & $\begin{array}{l}\text { CV disease and } \\
\text { CV mortality }\end{array}$ \\
\hline
\end{tabular}

Abbreviations: BP, blood pressure; OSA, obstructive sleep apnea; CV, cardiovascular; RYGB, Roux- en-Y gastric bypass; SAGB, single anastomosis gastric bypass; SG, sleeve gastrectomy; GB, gastric banding; SADI-S, single anastomosis duodeno-ileal bypass with sleeve gastrectomy; DS, duodenal switch.

(hazard ratio [HR] 0.43) and cardiovascular death (HR 0.15) was observed in the RYGB group. The differences were most marked with regards to stroke (HR 0.18) and heart failure (HR 0.32).

In summary, bariatric surgery in T1D patients with severe obesity has proved efficient in reducing weight and insulin dose and in improving associated comorbidities, with recent studies showing a significant reduction in cardiovascular disease and mortality. These benefits outweigh the adverse events observed, such as an increased risk of hypoglycemia and DKA. Nevertheless, a close monitoring of these patients by a multidisciplinary team is fundamental to provide a tailored, modifiable insulin regimen during all phases of management along 
with diabetes care and education. New diabetes technologies such as real-time monitorization may be especially helpful in this situation.

\section{Endoscopic procedures}

Endoscopic procedures are emerging as obesity treatment options but no studies have been published so far in T1D. These procedures are minimally invasive, most are reversible, safer and less costly compared to surgical treatment. However, they are characterized by the transience of their effects and the lack of long-term studies, so that for the time being their recommendation as primary treatments of obesity is not well established. ${ }^{54,62}$

\section{Future Perspectives}

Non-traditional therapies for patients with T1D and obesity need to be evaluated in the near future. ${ }^{173}$ In this way, pegylated fibroblast growth factor-21 appears as a novel metabolic regulator with the potential to become a powerful therapy to treat diabetes mellitus. ${ }^{174}$ Similarly, adiponectin ameliorates non-alcoholic fatty liver disease in streptozotocin-induced T1D. ${ }^{175}$ Finally, it still needs to be established whether immunotherapy may find a place in the prevention of progression to overt T1D and improve clinical outcomes in established diabetes in patients with obesity. ${ }^{176}$ On the other hand, there is an area of research in the development of strategies based on reducing oxidative stress in patients with T1D and obesity with some evidence coming from supplementation with probiotic/symbiotic and a low dietary intake of advanced glycation end products. ${ }^{177,178}$

An extensive pipeline of obesity medications is currently in Phase II and III development in adults, suggesting that more effective treatments will be available in the coming years. Some examples are the future combinations of drugs such as GLP1 agonists with GIP, Glucagon, or oxynomodulin (dual agonists or triagonists), the combination of Semaglutide with an amylin analog (Cagrilintide) $^{179}$ or the novel Bimagrumab which is a monoclonal antibody that binds to the type II activin receptor that regulates skeletal muscle growth, but also decreases adipose tissue improving insulin resistance. ${ }^{180}$

Undoubtedly, the big step ahead in the treatment of T1D and obesity will be provided by advances in precision medicine. Regarding this, the integration of major technological advances achieved in recent years (including highresolution omic assays, wearable devices that monitor behavior and exposure, and digital imaging technologies) integrated with genetic information will help individualize the efficacy of specific dietary approaches and select medication and surgical techniques for each patient. ${ }^{181}$ The introduction of this tailored treatment will definitively enhance the outcomes.

\section{Conclusions}

The coexistence of obesity and T1D is a growing problem and poses a challenge for effective glycemic and weight management. All patients should be offered a lifestyle intervention by a multidisciplinary team including a balanced hypocaloric diet, physical activity and cognitive behavioral therapy. In the "roadmap" of the treatment of obesity in T1D, it will be helpful to include approved anti-obesity pharmacotherapy, and in case of morbid obesity, bariatric surgery stands out as an effective procedure to reduce weight and comorbid conditions. In the near future, the development of new and more effective antiobesity treatments, coupled with strategies to improve insulin resistance and oxidative stress and advances in precision medicine, will provide very useful tools to improve both the weight and metabolic management of these patients.

\section{Acknowledgments}

We would like to thank The Obesity Group of the Spanish Society of Endocrinology and Nutrition (GOSEEN) for participating and providing data for this review. The authors would like to thank Dr. Jonathan Rogerson for his valuable help with the English version of the manuscript. We thank CERCA Programme Generalitat de Catalunya for institutional support.

\section{Funding}

$\mathrm{NV}$ is the recipient of grants "Ajuts per a projectes de recerca clínica de L'Hospital Universitari de Bellvitge (2011-PR143/11)" and of the project "PI11/01960; PI14/ 01997 and PI17/01556" funded by the Instituto de Salud Carlos III and co-funded by the European Union (ERDF, "A way to build Europe"). AL is the recipient of grant PI18/00964. The Spanish Biomedical Research Center in Diabetes and Associated Metabolic Disorders (CIBERDEM) (CB07708/0012) is an initiative of the Instituto de Salud Carlos III. 


\section{Disclosure}

The authors report no conflicts of interest in this work.

\section{References}

1. Afshin A, Forouzanfar MH, Reitsma MB, et al.; GBD 2015 Obesity Collaborators. Effects of overweight and obesity in 195 countries over 25 years. $N$ Engl $J$ Med. 2017;377(1):13-27. doi:10.1056/NEJMoa1614362

2. Corbin KD, Driscoll KA, Pratley RE, Smith SR, Maahs DM, Mayer-Davis EJ. Advancing care for Type 1 diabetes and obesity network (ACT1ON). Obesity in type 1 diabetes: pathophysiology, clinical impact, and mechanisms. Endocr Rev. 2018;39:629-663. doi:10.1210/er.2017-00191

3. American Diabetes Association. 2. Classification and diagnosis of diabetes: standards of medical care in diabetes-2021. Diabetes Care. 2021;44(Supp11):S15-S33. doi:10.2337/dc21-S002

4. Polsky S, Ellis SL. Obesity, insulin resistance, and type 1 diabetes mellitus. Curr Opin Endocrinol Diabetes Obes. 2015;22: 277-282. doi:10.1097/MED.0000000000000170

5. Pinhas-Hamiel O, Levek-Motola N, Kaidar K, et al. Prevalence of overweight, obesity and metabolic syndrome components in children, adolescents and young adults with type 1 diabetes mellitus. Diabetes Metab Res Rev. 2015;31:76-84. doi:10.1002/dmrr.2565

6. Minges KE, Whittemore R, Weinzimer SA, Irwin ML, Redeker NS, Grey M. Correlates of overweight and obesity in 5529 adolescents with type 1 diabetes: the T1D Exchange Clinic Registry. Diabetes Res Clin Pract. 2017;126:68-78. doi:10.1016/ j.diabres.2017.01.012

7. Fröhlich-Reiterer EE, Rosenbauer J, Bechtold-Dalla Pozza S, Hofer SE, Schober E, Holl RW. Predictors of increasing BMI during the course of diabetes in children and adolescents with type 1 diabetes: data from the German/Austrian DPV multicentre survey. Arch Dis Child. 2014;99:738-743. doi:10.1136/archdischild-2013-304237

8. DuBose SN, Hermann JM, Tamborlane WV, et al. Type 1 Diabetes Exchange Clinic Network and Diabetes Prospective Follow-up Registry. Obesity in youth with type 1 diabetes in Germany, Austria, and the United States. $J$ Pediatr. 2015;167:627-632. doi:10.1016/j.jpeds.2015.05.046

9. Liu LL, Lawrence JM, Davis C, et al.; SEARCH for Diabetes in Youth Study Group. Prevalence of overweight and obesity in youth with diabetes in USA: the SEARCH for Diabetes in Youth study. Pediatr Diabetes. 2010;11:4-11. doi:10.1111/j.13995448.2009.00519.x

10. Vestberg D, Rosengren A, Olsson M, Gudbjörnsdottir S, Svensson AM, Lind M. Relationship between overweight and obesity with hospitalization for heart failure in 20,985 patients with type 1 diabetes: a population-based study from the Swedish National Diabetes Registry. Diabetes Care. 2013;36:2857-2861. doi:10.2337/dc12-2007

11. Holt SK, Lopushnyan N, Hotaling J, et al. Diabetes Control and Complications Trial/Epidemiology of Diabetes Interventions and Complications Research Group. Prevalence of low testosterone and predisposing risk factors in men with type 1 diabetes mellitus: findings from the DCCT/EDIC. J Clin Endocrinol Metab. 2014;99:E1655-1660. doi:10.1210/jc.2014-1317

12. Fourlanos S, Elkassaby S, Varney MD, Colman PG, Harrison LC. Higher body mass index in adults at diagnosis of the slowly progressive form of type 1 diabetes mellitus is associated with lower risk HLA genes. Diabetes Res Clin Pract. 2014;104:e6971. doi:10.1016/j.diabres.2014.03.009

13. Islam ST, Abraham A, Donaghue KC, et al. Plateau of adiposity in Australian children diagnosed with Type 1 diabetes: a 20-year study. Diabet Med. 2014;31:686-690. doi:10.1111/dme.12402
14. Baskaran C, Volkening LK, Diaz M, Laffel LM. A decade of temporal trends in overweight/obesity in youth with type 1 diabetes after the Diabetes Control and Complications Trial. Pediatr Diabetes. 2015;16:263-270. doi:10.1111/pedi.12166

15. Conway B, Miller RG, Costacou T, et al. Temporal patterns in overweight and obesity in type 1 diabetes. Diabet Med. 2010;27:398-404. doi:10.1111/j.1464-5491.2010.02956.x

16. Nathan DM, Zinman B, Cleary PA, et al.; Diabetes Control and Complications Trial/Epidemiology of Diabetes Interventions and Complications (DCCT/EDIC) Research Group. Modern-day clinical course of type 1 diabetes mellitus after 30 years' duration: the diabetes control and complications trial/ epidemiology of diabetes interventions and complications and Pittsburgh epidemiology of diabetes complications experience (1983-2005). Arch Intern Med. 2009;169:1307-1316. doi:10.1001/archinternmed.2009.193

17. Verbeeten KC, Elks CE, Daneman D, Ong KK. Association between childhood obesity and subsequent Type 1 diabetes: a systematic review and meta-analysis. Diabet Med. 2011;28:10-18. doi:10.1111/j.1464-5491.2010.03160.x

18. Harder T, Roepke K, Diller N, Stechling Y, Dudenhausen JW, Plagemann A. Birth weight, early weight gain, and subsequent risk of Type 1 diabetes: systematic review and meta-analysis. $\mathrm{Am}$ J Epidemiol. 2009;169:1428-1436. doi:10.1093/aje/kwp065

19. Betts $P$, Mulligan J, Ward P, et al. Increasing body weight predicts the earlier onset of insulin-dependent diabetes in childhood: testing the 'accelerator hypothesis' (2). Diabet Med. 2005;22:144-151. doi:10.1111/j.1464-5491.2004.01368.x

20. Svensson J, Carstensen B, Mortensen HB, Borch-Johnsen K. Growth in the first year of life and the risk of type 1 diabetes in a Danish population. Paediatr Perinat Epidemiol. 2007;21:44-48. doi:10.1111/j.1365-3016.2007.00775.x

21. EURODIAB Substudy 2 Study Group. Rapid early growth is associated with increased risk of childhood Type 1 diabetes in various European populations. Diabetes Care. 2002;25:17 55-1760. doi:10.2337/diacare.25.10.1755

22. Hypponen E, Virtanen SM, Kenward MG, Knip M, Akerblom HK. Obesity, increased linear growth, and risk of Type 1 diabetes in children. Diabetes Care. 2000;23:1755-1760. doi:10.2337/diacare.23.12.1755

23. Viner RM, Hindmarsh PC, Taylor B, et al. Childhood body mass index (BMI), breastfeeding and risk of Type 1 diabetes: findings from a longitudinal national birth cohort. Diabet Med. 2008;25:1056-1061. doi:10.1111/j.1464-5491.2008.02525.x

24. Berhan Y, Waernbaum I, Lind T, Möllsten A, Dahlquist G; Swedish Childhood Diabetes Study Group. Thirty years of prospective nationwide incidence of childhood type 1 diabetes: the accelerating increase by time tends to level off in Sweden. Diabetes. 2011;60:577-581. doi:10.2337/db10-0813

25. Bruining GJ. Association between infant growth before onset of juvenile type-1 diabetes and autoantibodies to IA-2. Lancet. 2000;356:655-656. doi:10.1016/s0140-6736(00)02612-x

26. Lammi N, Moltchanova E, Blomstedt PA, Tuomilehto J, Eriksson JG, Karvonen M. Childhood BMI trajectories and the risk of developing young adult onset diabetes. Diabetologia. 2009;52:408-414. doi:10.1007/s00125-008-1244-0

27. González-álvarez MA, Lázaro-Alquézar A, Simón-Fernández MB. Global trends in child obesity: are figures converging? Int J Environ Res Public Health. 2020;17(24):9252. doi:10.3390/ijerph17249252

28. Wilkin TJ. The convergence of type 1 and type 2 diabetes in childhood: the accelerator hypothesis. Pediatr Diabetes. 2012;13:334-339. doi:10.1111/j.1399-5448.2011.00831.x

29. Tang C, Naassan AE, Chamson-Reig A, et al. Susceptibility to fatty acid-induced $\beta$-cell dysfunction is enhanced in prediabetic diabetes-prone biobreeding rats: a potential link between $\beta$-cell lipotoxicity and islet inflammation. Endocrinology. 2013;15 4:89-101. doi:10.1210/en.2012-1720 
30. Tsui H, Paltser G, Chan Y, Dorfman R, Dosch HM. 'Sensing' the link between type 1 and type 2 diabetes. Diabetes Metab Res Rev. 2011;27:913-918. doi:10.1002/dmrr.1279

31. Găman MA, Epîngeac ME, Diaconu CC, Găman AM. Evaluation of oxidative stress levels in obesity and diabetes by the free oxygen radical test and free oxygen radical defence assays and correlations with anthropometric and laboratory parameters. World J Diabetes. 2020;11(5):193-201. doi:10.4239/wjd.v11.i5.193

32. Yang Y, Torchinsky MB, Gobert M, et al. Focused specificity of intestinal TH17 cells towards commensal bacterial antigens. Nature. 2014;510:152-156. doi:10.1038/nature13279

33. Tai N, Wong FS, Wen L. The role of gut microbiota in the development of type 1, type 2 diabetes mellitus and obesity. Rev Endocr Metab Disord. 2015;16:55-65. doi:10.1007/s11154-015-9309-0

34. Grant SFA. The TCF7L2 locus: a genetic window into the pathogenesis of type 1 and type 2 diabetes. Diabetes Care. 2019;42:1624-1629. doi:10.2337/dci19-0001

35. Field SF, Howson JM, Smyth DJ, Walker NM, Dunger DB, Todd JA. Analysis of the type 2 diabetes gene, TCF7L2, in 13,795 type 1 diabetes cases and control subjects. Diabetologia. 2007;50:212-213. doi:10.1007/s00125-006-0506-y

36. Redondo MJ, Geyer S, Steck AK, et al.; Type 1 Diabetes TrialNet Study Group. TCF7L2 genetic variants contribute to phenotypic heterogeneity of type 1 diabetes. Diabetes Care. 2018;41:31 1-317. doi:10.2337/dc17-0961

37. Purnell JQ, Hokanson JE, Marcovina SM, Steffes MW, Cleary PA, Brunzell JD. Effect of excessive weight gain with intensive therapy of type 1 diabetes on lipid levels and blood pressure: results from the DCCT. Diabetes Control and Complications Trial. JAMA. 1998;280(2):140-146. Erratum in: JAMA 1998 Nov 4;280(17):1484. doi:10.1001/jama.280.2.140

38. Purnell JQ, Zinman B, Brunzell JD. The effect of excess weight gain with intensive diabetes mellitus treatment on cardiovascular disease risk factors and atherosclerosis in type 1 diabetes mellitus: results from the Diabetes Control and Complications Trial/ Epidemiology of Diabetes Interventions and Complications Study (DCCT/EDIC) study. Circulation. 2013;127(2):180-187. doi:10.1161/CIRCULATIONAHA.111.077487

39. Teupe B, Bergis K. Epidemiological evidence for "double diabetes". Lancet (London, England). 1991;337(8737):361-362. doi:10.1016/0140-6736(91)90988-2

40. Chillarón JJ, Flores Le-roux JA, Benaiges D, Pedro-Botet J. Type 1 diabetes, metabolic syndrome and cardiovascular risk. Metabolism. 2014;63(2):181-187. doi:10.1016/j.metabol.2013.10.002

41. Rodrigues TC, Veyna AM, Haarhues MD, Kinney GL, Rewers M, Snell-Bergeon JK. Obesity and coronary artery calcium in diabetes: the Coronary Artery Calcification in Type 1 Diabetes (CACTI) study. Diabetes Technol Ther. 2011;13:991-996. doi:10.1089/dia.2011.0046

42. Price SA, Gorelik A, Fourlanos S, Colman PG, Wentworth JM. Obesity is associated with retinopathy and macrovascular disease in type 1 diabetes. Obes Res Clin Pract. 2014;8:e178-e182. doi:10.1016/j.orcp.2013.03.007

43. Kaštelan S, Salopek Rabatić J, Tomić M, et al. Body mass index and retinopathy in type 1 diabetic patients. Int $J$ Endocrinol. 2014;2014:387919. doi:10.1155/2014/387919

44. Dobrică EC, Găman MA, Cozma MA, Bratu OG, Pantea Stoian A, Diaconu CC. Polypharmacy in type 2 diabetes mellitus: insights from an internal medicine department. Medicina (Kaunas). 2019;55(8):436. doi:10.3390/medicina55080436

45. American Diabetes Association. Pharmacologic approaches to glycemic treatment: standards of medical care in diabetes. 2021. Diabetes Care. 2021;44(Supp11):S111-S124. doi:10.2337/dc21-S009

46. The DCCT Research Group. The effect of intensive treatment of diabetes on the development and progression of long-term complications in insulin-dependent diabetes mellitus. $N$ Engl $J$ Med. 1993;329:977-986. doi:10.1056/NEJM199309303291401
47. Mattes R, Foster GD. Food environment and obesity. Obesity (Silver Spring). 2014;22(12):2459-2461. doi:10.1002/oby.20922

48. Solmi M, Ioannidis JPA, Carvalho AF. Environmental risk factors and interventions for obesity. Eur J Clin Invest. 2019;49(5): e13080. doi:10.1111/eci.13080

49. Durrer Schutz D, Busetto L, Dicker D, et al. European practical and patient-centred guidelines for adult obesity management in primary care. Obes Facts. 2019;12(1):40-66. doi:10.1159/ 000496183

50. Woods SC, Lutz TA, Geary N, Langhans W. Pancreatic signals controlling food intake; insulin, glucagon and amylin. Philos Trans $R$ Soc Lond B Biol Sci. 2006;361(1471):1219-1235. doi:10.1098/rstb.2006.1858

51. Dinneen S, Alzaid A, Turk D, Rizza R. Failure of glucagon suppression contributes to postprandial hyperglycaemia in IDDM. Diabetologia. 1995;38:337-343. doi:10.1007/BF00400 639

52. Zaharieva DP, Addala A, Simmons KM, Maahs DM. Weight management in youth with type 1 diabetes and obesity: challenges and possible solutions. Curr Obes Rep. 2020;9(4):412-423. doi:10.1007/s13679-020-00411-z

53. Mottalib A, Tomah S, Hafida S, et al. Intensive multidisciplinary weight management in patients with type 1 diabetes and obesity: a one-year retrospective matched cohort study. Diabetes Obes Metab. 2019;21(1):37-42. doi:10.1111/dom.13478

54. Garvey WT, Mechanick JI, Brett EM, et al. American Association of Clinical Endocrinologists and American College of Endocrinology Comprehensive Clinical Practice Guidelines for Medical Care of Patients with Obesity. Endocr Pract. 2016;22 (suppl 3):1-230. doi:10.4158/EP161365.GL

55. Kahkoska AR, Watts ME, Driscoll KA, et al. Understanding antagonism and synergism: a qualitative assessment of weight management in youth with type 1 diabetes mellitus. Obes Med. 2018;9:21-31. doi:10.1016/j.obmed.2017.12.001

56. Dornhorst A, Lüddeke HJ, Sreenan S, et al.; PREDICTIVE Study Group. Insulin detemir improves glycaemic control without weight gain in insulin-naïve patients with type 2 diabetes: subgroup analysis from the PREDICTIVE study. Int $J$ Clin Pract. 2008;62(4):659-665. doi:10.1111/j.1742-1241.2008.01715.x

57. Holmes RS, Crabtree E, McDonagh MS. Comparative effectiveness and harms of long-acting insulins for type 1 and type 2 diabetes: a systematic review and meta-analysis. Diabetes Obes Metab. 2019;21(4):984-992. doi:10.1111/dom.13614

58. Madenidou AV, Paschos P, Karagiannis T, et al. Comparative benefits and harms of basal insulin analogues for type 2 diabetes: a systematic review and network meta-analysis. Ann Intern Med. 2018;169(3):165-174. doi:10.7326/M18-0443

59. Blair JC, McKay A, Ridyard C. Continuous subcutaneous insulin infusion versus multiple daily injection regimens in children and young people at diagnosis of type 1 diabetes: pragmatic randomised controlled trial and economic evaluation. BMJ. 2019;365:11226. doi:10.1136/bmj.11226

60. Alderisio A, Bozzetto L, Franco L, Riccardi G, Rivellese AA, Annuzzi G. Long-term body weight trajectories and metabolic control in type 1 diabetes patients on insulin pump or multiple daily injections: a 10-year retrospective controlled study. Nutr Metab Cardiovasc Dis. 2019;29(10):1110-1117. doi:10.1016/j.numecd.2019.06.008

61. American Diabetes Association. Facilitating behavior change and well-being to improve health outcomes: standards of medical care in diabetes-2021. Diabetes Care. 2021;44(Suppl1):S53-S72. doi:10.2337/dc21-S005

62. Ballesteros Pomar MD, Vilarrasa García N, Rubio Herrera MÁ, et al. The SEEN comprehensive clinical survey of adult obesity: executive summary. Endocrinol Diabetes Nutr. 2021;68 (2):130-136. doi:10.1016/j.endinu.2020.05.003 
63. American Diabetes Association. Children and adolescents: standards of medical care in diabetes-2021. Diabetes Care. 2021;44 (Supp11):S180-S199. doi:10.2337/dc21-S013

64. Estruch R, Ros E, Salas-Salvadó J, et al. Primary prevention of cardiovascular disease with a Mediterranean diet. $N$ Engl J Med. 2013;368(14):1279-1290. doi:10.1056/NEJMoa1200303

65. Sofi F, Abbate R, Gensini GF, Casini A. Accruing evidence on benefits of adherence to the Mediterranean diet on health: an updated systematic review and meta-analysis. Am J Clin Nutr. 2010;92(5):1189-1196. doi:10.3945/ajen.2010.29673

66. Fortin A, Rabasa-Lhoret R, Lemieux S, Labonté ME, Gingras V. Comparison of a Mediterranean to a low-fat diet intervention in adults with type 1 diabetes and metabolic syndrome: a 6-month randomized trial. Nutr Metab Cardiovasc Dis. 2018;28 (12):1275-1284. doi:10.1016/j.numecd.2018.08.005

67. Scott SN, Anderson L, Morton JP, Wagenmakers AJM, Riddell MC. Carbohydrate restriction in type 1 diabetes: a realistic therapy for improved glycaemic control and athletic performance? Nutrients. 2019;11(5):1022. doi:10.3390/nu11051022

68. Ranjan A, Schmidt S, Damm-Frydenberg C, et al. Lowcarbohydrate diet impairs the effect of glucagon in the treatment of insulin-induced mild hypoglycemia: a Randomized Crossover Study. Diabetes Care. 2017;40(1):132-135. doi:10.2337/dc161472

69. Eiswirth M, Clark E, Diamond M. Low carbohydrate diet and improved glycaemic control in a patient with type one diabetes. Endocrinol Diabetes Metab Case Rep. 2018;2018:18. doi:10.1530/EDM-18-0002

70. Krebs JD, Strong AP, Cresswell P, Reynolds AN, Hanna A, Haeusler S. A randomised trial of the feasibility of a low carbohydrate diet vs standard carbohydrate counting in adults with type 1 diabetes taking body weight into account. Asia Pac J Clin Nutr. 2016;25:78-84. doi:10.6133/apjen.2016.25.1.11

71. Nielsen JV, Jönsson E, Ivarsson A. A low carbohydrate diet in type 1 diabetes: clinical experience-A brief report. Upsala J Med Sci. 2005;110:267-273. doi:10.3109/2000-1967-074

72. Schmidt S, Christensen MB, Serifovski N, et al. Low versus high carbohydrate diet in type 1 diabetes: a 12-week randomized open-label crossover study. Diabetes Obes Metab. 2019;21 (7):1680-1688. doi:10.1111/dom.13725

73. Turton JL, Raab R, Rooney KB. Low-carbohydrate diets for type 1 diabetes mellitus: a systematic review. PLoS One. 2018;13(3): e0194987. doi:10.1371/journal.pone.0194987

74. Rynders CA, Thomas EA, Zaman A, Pan Z, Catenacci VA, Melanson EL. Effectiveness of intermittent fasting and time-restricted feeding compared to continuous energy restriction for weight loss. Nutrients. 2019;11(10):pii: E2442. doi:10.3390/ nu11102442

75. Cioffi I, Evangelista A, Ponzo V, et al. Intermittent versus continuous energy restriction on weight loss and cardiometabolic outcomes: a systematic review and meta-analysis of randomized controlled trials. J Transl Med. 2018;16(1):371. doi:10.1186/ s12967-018-1748-4

76. Absil H, Baudet L, Robert A, Lysy PA. Benefits of physical activity in children and adolescents with type 1 diabetes: a systematic review. Diabetes Res Clin Pract. 2019;156:107810. doi:10.1016/j.diabres.2019.107810

77. Sundberg F, Forsander G, Fasth A, Ekelund U. Children younger than 7 years with type 1 diabetes are less physically active than healthy controls. Acta Paediatr. 2012;101:1164-1169. doi:10.1111/j.1651-2227.2012.02803.x

78. Roberts AJ, Taplin CE, Isom S, et al. Association between fear of hypoglycemia and physical activity in youth with type 1 diabetes: the SEARCH for diabetes in youth study. Pediatr Diabetes. 2020;21(7):1277-1284. doi:10.1111/pedi.13092
79. Taplin CE, Cobry E, Messer L, McFann K, Chase HP, FialloScharer R. Preventing post-exercise nocturnal hypoglycemia in children with type 1 diabetes. J Pediatr. 2010;157:784-788.e1. doi:10.1016/j.jpeds.2010.06.004

80. Baker LB, Rollo I, Stein KW, Jeukendrup AE. Acute effects of carbohydrate supplementation on intermittent sports performance. Nutrients. 2015;7:5733-5763. doi:10.3390/nu7075249

81. Czenczek-Lewandowska E, Grzegorczyk J, Mazur A. Physical activity in children and adolescents with type 1 diabetes and contem-porary methods of its assessment. Pediatr Endocrinol Diabetes Metab. 2018;24(4):179-184. doi:10.5114/pedm.2018. 83364

82. Rubino F, Puhl RM, Cummings DE, et al. Joint international consensus statement for ending stigma of obesity. Nat Med. 2020;26(4):485-497. doi:10.1038/s41591-020-0803-x

83. Magallares A, Pais-Ribeiro JL. Mental health and obesity: a meta-analysis. Appl Res Qual Life. 2014;9:295-308. doi:10. 1080/13548506.2014.963627

84. Wisting L, Skrivarhaug T, Dahl-Jørgensen K, Rø Ø. Prevalence of disturbed eating behavior and associated symptoms of anxiety and depression among adult males and females with type 1 diabetes. J Eat Disord. 2018;6:28. doi:10.1186/s40337-018-0209-z

85. Young V, Eiser C, Johnson B, et al. Eating problems in adolescents with type 1 diabetes: a systematic review with meta-analysis. Diabet Med. 2013;30:189-198. doi:10.1111/ j.1464-5491.2012.03771.x

86. Palavras MA, Kaio GH, Mari J, Claudino AM. A review of Latin American studies on binge eating disorder. Rev Bras Psiquiatr. 2011;33:s81-s94. doi:10.1590/s1516-44462011000500007

87. Villarejo C, Fernandez-Aranda F, Jimenez-Murcia S, et al. Lifetime obesity in patients with eating disorders: increasing prevalence, clinical and personality correlates. Eur Eat Disord Rev. 2012;20:250-254. doi:10.1002/erv.2166

88. Bryden KS, Neil A, Mayou RA, Peveler RC, Fairburn CG, Dunger DB. Eating habits, body weight, and insulin misuse. A longitudinal study of teenagers and young adults with type 1 diabetes. Diabetes Care. 1999;22:1956-1960. doi:10.1002/erv.2166

89. Pinhas-Hamiel O, Hamiel U, Levy-Shraga Y. Eating disorders in adolescents with type 1 diabetes: challenges in diagnosis and treatment. World J Diabetes. 2015;6:517-526. doi:10.4239/wjd. v6.i3.517

90. Toni G, Berioli MG, Cerquiglini L, et al. Eating disorders and disordered eating symptoms in adolescents with type 1 diabetes. Nutrients. 2017;9(8):906. doi:10.3390/nu9080906

91. Markowitz JT, Alleyn CA, Phillips R, Muir A, Young-Hyman D, Laffel LM. Disordered eating behaviors in youth with type 1 diabetes: prospective pilot assessment following initiation of insulin pump therapy. Diabetes Technol Ther. 2013;15(5):428-433. doi:10.1089/dia.2013.0008

92. Rucker D, Padwal R, Li SK, Curioni C, Lau DC. Long term pharmacotherapy for obesity and overweight: updated meta-analysis. BMJ. 2007;335(7631):1194-1199. doi:10.1136/ bmj.39385.413113.25

93. Greenway FL, Fujioka K, Plodkowski RA, et al. Effect of naltrexone plus bupropion on weight loss in overweight and obese adults (COR-I): a multicentre, randomised, double-blind, placebo-controlled, Phase 3 trial. Lancet. 2010;376:595-605. doi:10.1016/S0140-6736(10)60888-4

94. Apovian CM, Aronne L, Rubino D, et al.; COR-II Study Group. A randomized, phase 3 trial of naltrexone SR/bupropion SR on weight and obesity-related risk factors (COR-II). Obesity (Silver Spring). 2013;21:935-943. doi:10.1002/oby.20309

95. Wadden TA, Foreyt JP, Foster GD, et al. Weight loss with naltrexone SR/bupropion SR combination therapy as an adjunct to behavior modification: the COR-BMOD trial. Obesity (Silver Spring). 2011;19:110-120. doi:10.1038/oby.2010.147 
96. Hollander P, Gupta AK, Plodkowski R, et al.; COR-Diabetes Study Group. Effects of naltrexone sustained-release/bupropion sustained-release combination therapy on body weight and glycemic parameters in overweight and obese patients with type 2 diabetes. Diabetes Care. 2013;36(12):4022-4029. doi:10.2337/dc13-0234

97. Gadde KM, Allison DB, Ryan DH, et al. Effects of low dose, controlled-release, phentermine plus topiramate combination on weight and associated comorbidities in overweight and obese adults (CONQUER): a randomised, placebo-controlled, phase 3 trial. Lancet. 2011;377(9774):1341-1352. doi:10.1016/S01406736(11)60205-5

98. Allison DB, Gadde KM, Garvey WT, et al. Controlled-release phentermine/topiramate in severely obese adults: a randomized controlled trial (EQUIP). Obesity (Silver Spring). 2012;20 (2):330-342. doi:10.1038/oby.2011.330

99. Garvey WT, Ryan DH, Look M, et al. Two-year sustained weight loss and metabolic benefits with controlled-release phentermine/ topiramate in obese and overweight adults (SEQUEL): a randomized, placebo-controlled, phase 3 extension study. $\mathrm{Am}$ J Clin Nutr. 2012;95(2):297-308. doi:10.3945/ajen.111.024927

100. Garvey WT, Ryan DH, Bohannon NJ, et al. Weight-loss therapy in type 2 diabetes: effects of phentermine and topiramate extended release. Diabetes Care. 2014;37(12):3309-3316. doi:10.2337/dc14-0930

101. Pi-Sunyer X, Astrup A, Fujioka K, et al. A Randomized, Controlled Trial of $3.0 \mathrm{mg}$ of liraglutide in weight management. New Engl J Med. 2015;373:11-22. doi:10.1056/NEJMoa1411892

102. Le Roux CW, Astrup A, Fujioka K, et al. 3 years of liraglutide versus placebo for type 2 diabetes risk reduction and weight management in individuals with prediabetes: a randomised, double-blind trial. Lancet. 2017;389:1399-1409. doi:10.1016/S0140-6736(17)30069-7

103. Davies MJ, Aronne LJ, Caterson ID, Thomsen AB, Jacobsen PB, Marso SP. Liraglutide and cardiovascular outcomes in adults with overweight or obesity: a post hoc analysis from SCALE randomized controlled trials. Diabetes Obes Metab. 2018;20:734-739. doi:10.1111/dom.13125

104. Davies MJ, Bergenstal R, Bode B, et al.; NN8022-1922 Study Group. Efficacy of liraglutide for weight loss among patients with type 2 diabetes: the SCALE Diabetes Randomized Clinical Trial. JAMA. 2015;314(7):687-699. doi:10.1001/jama.2015.9676

105. Kelly AS, Auerbach P, Barrientos-Perez M, et al.; NN8022-4180 Trial Investigators. A Randomized, Controlled Trial of Liraglutide for Adolescents with Obesity. $N$ Engl $J$ Med. 2020;382(22):2117-2128. doi:10.1056/NEJMoa1916038

106. Pratley RE, Aroda VR, Lingvay I, et al.; SUSTAIN 7 investigators. Semaglutide versus dulaglutide once weekly in patients with type 2 diabetes (SUSTAIN 7): a randomised, open-label, phase 3b trial. Lancet Diabetes Endocrinol. 2018;6(4):275-286. doi:10.1016/S2213-8587(18)30024-X

107. Wilding JPH, Batterham RL, Calanna S, et al.; STEP 1 Study Group. Once-weekly semaglutide in adults with overweight or obesity. $N$ Engl $J$ Med. 2021;384(11):989. doi:10.1056/ NEJMoa2032183

108. Davies M, Færch L, Jeppesen OK, et al.; STEP 2 Study Group. Semaglutide $2.4 \mathrm{mg}$ once a week in adults with overweight or obesity, and type 2 diabetes (STEP 2): a randomised, doubleblind, double-dummy, placebo-controlled, phase 3 trial. Lancet. 2021;397(10278):971-984. doi:10.1016/S0140-6736(21)00213-0

109. Holst JJ, Rosenkilde MM. GIP as a therapeutic target in diabetes and obesity: insight from incretin co-agonists. $J$ Clin Endocrinol Metab. 2020;105(8):e2710-6. doi:10.1210/clinem/dgaa327

110. Rena G, Hardie DG, Pearson ER. The mechanisms of action of metformin. Diabetologia. 2017;60(9):1577-1585. doi:10.1007/ s00125-017-4342-z
111. Jacobsen IB, Henriksen JE, Beck-Nielsen H. The effect of metformin in overweight patients with type 1 diabetes and poor metabolic control. Basic Clin Pharmacol Toxicol. 2009;105 (3):145-149. doi:10.1111/j.1742-7843.2009.00380.x

112. Lund SS, Tarnow L, Astrup AS, et al. Effect of adjunct metformin treatment in patients with type- 1 diabetes and persistent inadequate glycaemic control. A randomized study. PLoS One. 2008;3 (10):e3363. doi:10.1371/journal.pone.0003363

113. Petrie JR, Chaturvedi N, Ford I, et al.; REMOVAL Study Group. Cardiovascular and metabolic effects of metformin in patients with type 1 diabetes (REMOVAL): a double-blind, randomised, placebo-controlled trial. Lancet Diabetes Endocrinol. 2017;5 (8):597-609. doi:10.1016/S2213-8587(17)30194-8

114. Pörksen S, Nielsen LB, Kaas A, et al.; Hvidøre Study Group on Childhood Diabetes. Meal-stimulated glucagon release is associated with postprandial blood glucose level and does not interfere with glycemic control in children and adolescents with new-onset type 1 diabetes. J Clin Endocrinol Metab. 2007;92 (8):2910-2916. doi:10.1210/jc.2007-0244

115. Griffin KJ, Thompson PA, Gottschalk M, Kyllo JH, Rabinovitch A. Combination therapy with sitagliptin and lansoprazole in patients with recent-onset type 1 diabetes (REPAIR-T1D): 12-month results of a multicentre, randomised, placebo-controlled, Phase 2 trial. Lancet Diabetes Endocrinol. 2014;2(9):710-718. doi:10.1016/S2213-8587(14)70115-9

116. Ellis SL, Moser EG, Snell-Bergeon JK, Rodionova AS, Hazenfield RM, Garg SK. Effect of sitagliptin on glucose control in adult patients with Type 1 diabetes: a pilot, double-blind, randomized, crossover trial. Diabet Med. 2011;28 (10):1176-1181. doi:10.1111/j.1464-5491.2011.03331.x

117. Traina AN, Lull ME, Hui AC, Zahorian TM, Lyons-Patterson J. Once-weekly exenatide as adjunct treatment of type 1 diabetes mellitus in patients receiving continuous subcutaneous insulin infusion therapy. Can J Diabetes. 2014;38(4):269-272. doi:10.1016/j.jcjd.2013.10.006

118. Hari Kumar KV, Shaikh A, Prusty P. Addition of exenatide or sitagliptin to insulin in new onset type 1 diabetes: a randomized, open label study. Diabetes Res Clin Pract. 2013;100(2):e55-8. doi:10.1016/j.diabres.2013.01.020

119. Jiang LL, Wang SQ, Ding B, et al. The effects of add-on exenatide to insulin on glycemic variability and hypoglycemia in patients with type 1 diabetes mellitus. $J$ Endocrinol Invest. 2018;41(5):539-547. doi:10.1007/s40618-017-0765-0

120. Dejgaard TF, Frandsen CS, Hansen TS, et al. Efficacy and safety of liraglutide for overweight adult patients with type 1 diabetes and insufficient glycaemic control (Lira-1): a randomised, double-blind, placebo-controlled trial. Lancet Diabetes Endocrinol. 2016;4 (3):221-232. doi:10.1016/S2213-8587(15)00436-2

121. Mathieu C, Zinman B, Hemmingsson JU, et al.; ADJUNCT ONE Investigators. Efficacy and safety of liraglutide added to insulin treatment in type 1 diabetes: the ADJUNCT ONE Treat-To-Target Randomized Trial. Diabetes Care. 2016;39(10):1702-1710. doi:10.2337/dc16-0691

122. Ahrén B, Hirsch IB, Pieber TR, et al.; ADJUNCT TWO Investigators. Efficacy and safety of liraglutide added to capped insulin treatment in subjects with type 1 diabetes: the ADJUNCT TWO Randomized Trial. Diabetes Care. 2016;39(10):1693-1701. doi: $10.2337 / \mathrm{dc} 16-0690$

123. Rieg T, Vallon V. Development of SGLT1 and SGLT2 inhibitors. Diabetologia. 2018;61(10):2079-2086. doi:10.1007/s00125-018-4654-7

124. Dandona P, Mathieu C, Phillip M, et al.; DEPICT-1 Investigators. Efficacy and safety of dapagliflozin in patients with inadequately controlled type 1 diabetes: the DEPICT-1 52-Week Study. Diabetes Care. 2018;41(12):2552-2559. doi:10.2337/dc18-1087 
125. Mathieu C, Dandona P, Gillard P, et al.; DEPICT-2 Investigators. Efficacy and safety of dapagliflozin in patients with inadequately controlled type 1 diabetes (the DEPICT-2 Study): 24-Week Results From a Randomized Controlled Trial. Diabetes Care. 2018;41(9):1938-1946. doi:10.2337/dc18-0623

126. Pieber TR, Famulla S, Eilbracht J, et al. Empagliflozin as adjunct to insulin in patients with type 1 diabetes: a 4-week, randomized, placebo-controlled trial (EASE-1). Diabetes Obes Metab. 2015;17(10):928-935. doi:10.1111/dom.12494

127. Rosenstock J, Marquard J, Laffel LM, et al. Empagliflozin as adjunctive to insulin therapy in type 1 diabetes: the EASE Trials. Diabetes Care. 2018;41(12):2560-2569. doi:10.2337/dc18-1749

128. Buse JB, Garg SK, Rosenstock J, et al. Sotagliflozin in combination with optimized insulin therapy in adults with type 1 diabetes: the North American inTandem1 Study. Diabetes Care. 2018;41 (9):1970-1980. doi:10.2337/dc18-0343

129. Danne T, Cariou B, Banks P, et al. HbA(1c) and hypoglycemia reductions at 24 and 52 weeks with sotagliflozin in combination with insulin in adults with type 1 diabetes: the European inTandem2 Study. Diabetes Care. 2018;41(9):1981-1990. doi:10.2337/dc18-0342

130. Garg SK, Henry RR, Banks P. Effects of sotagliflozin added to insulin in patients with type 1 diabetes. $N$ Engl J Med. 2017;377 (24):2337-2348. doi:10.1056/NEJMoa1708337

131. Hay DL, Chen S, Lutz TA, Parkes DG, Roth JD. Amylin: pharmacology, physiology, and clinical potential. Pharmacol Rev. 2015;67(3):564-600. doi:10.1124/pr.115.010629

132. Kruger DF, Gatcomb PM, Owen SK. Clinical implications of amylin and amylin deficiency. Diabetes Educ. 1999;25(3):38997; quiz 398. doi:10.1177/014572179902500310

133. Whitehouse F, Kruger DF, Fineman M, et al. A randomized study and open-label extension evaluating the long-term efficacy of pramlintide as an adjunct to insulin therapy in type 1 diabetes. Diabetes Care. 2002;25(4):724-730. doi:10.2337/diacare.25.4.724

134. Edelman S, Garg S, Frias J, et al. A double-blind, placebo-controlled trial assessing pramlintide treatment in the setting of intensive insulin therapy in type 1 diabetes. Diabetes Care. 2006;29(10):2189-2195. doi:10.2337/dc06-0042

135. Ratner RE, Dickey R, Fineman M, et al. Amylin replacement with pramlintide as an adjunct to insulin therapy improves long-term glycaemic and weight control in Type 1 diabetes mellitus: a 1-year, randomized controlled trial. Diabet Med. 2004;21 (11):1204-1212. doi:10.1111/j.1464-5491.2004.01319.x

136. Watanabe M, Risi R, Masi D, et al. Current evidence to propose different food supplements for weight loss: a comprehensive review. Nutrients. 2020;12(9):2873. doi:10.3390/nu12092873

137. Lin Y, Shi D, Su B, et al. The effect of green tea supplementation on obesity: a systematic review and dose-response meta-analysis of randomized controlled trials. Phytother Res. 2020;34 (10):2459-2470. doi:10.1002/ptr.6697

138. De Luca M, Angrisani L, Himpens J, et al. Indications for surgery for obesity and weight-related diseases: position statements from the International Federation for the Surgery of Obesity and Metabolic Disorders IFSO. Obes Surg. 2016;26:1659-1696. doi:10.1007/s11695-016-2271-4

139. Korakas E, Kountouri A, Raptis A, Kokkinos A, Lambadiari V. Bariatric surgery and type 1 diabetes: unanswered questions. Front Endocrinol (Lausanne). 2020;11:525909. doi:10.3389/fendo.2020.525909

140. Breen DM, Rasmussen BA, Kokorovic A, Wang R, Cheung GW, Lam TK. Jejunal nutrient sensing is required for duodenal-jejunal bypass surgery to rapidly lower glucose concentrations in uncontrolled diabetes. Nat Med. 2012;18(6):950-955. doi:10.1038/nm.2745

141. Dirksen C, Jacobsen SH, Bojsen-Møller KN, et al. Reduction in cardiovascular risk factors and insulin dose, but no beta-cell regeneration 1 year after Roux-en-Y gastric bypass in an obese patient with type 1 diabetes: a case report. Obes Res Clin Pract. 2013;7(4):e269-74. doi:10.1016/j.orcp.2012.01.002
142. Blanco J, Jiménez A, Casamitjana R, et al. Relevance of beta-cell function for improved glycemic control after gastric bypass surgery. Surg Obes Relat Dis. 2014;10(1):9-13;quiz 189-90. doi:10.1016/j.soard.2013.07.020

143. Czupryniak L, Strzelczyk J, Cypryk K, et al. Gastric bypass surgery in severely obese type 1 diabetic patients. Diabetes Care. 2004;27(10):2561-2562. doi:10.2337/diacare.27.10.2561

144. Czupryniak L, Wiszniewski M, Szymański D, Pawłowski M, Loba J, Strzelczyk J. Long-term results of gastric bypass surgery in morbidly obese type 1 diabetes patients. Obes Surg. 2010;20 (4):506-508. doi:10.1007/s11695-010-0074-6

145. Mendez CE, Tanenberg RJ, Pories W. Outcomes of Roux-en-Y gastric bypass surgery for severely obese patients with type 1 diabetes: a case series report. Diabetes Metab Syndr Obes. 2010;3:281-283. PMID: 21437096; PMCID: PMC3047955. doi:10.2147/DMSO.S9981

146. Fuertes-Zamorano N, Sánchez-Pernaute A, Torres García AJ, Rubio Herrera MA. Bariatric surgery in type 1 diabetes mellitus; long-term experience in two cases. Nutr Hosp. 2013;28 (4):1333-1336. doi:10.3305/nh.2013.28.4.6605

147. Chuang J, Zeller MH, Inge T, Crimmins N. Bariatric surgery for severe obesity in two adolescents with type 1 diabetes. Pediatrics. 2013;132(4):e1031-4. doi:10.1542/peds.2012-3640

148. Raab H, Weiner RA, Frenken M, Rett K, Weiner S. Obesity and metabolic surgery in type 1 diabetes mellitus. Nutr Hosp. 2013;28 (Suppl 2):31-34. doi:10.3305/nh.2013.28.sup2.6711

149. Middelbeek RJ, James-Todd T, Patti ME, Brown FM. Short-term insulin requirements following gastric bypass surgery in severely obese women with type 1 diabetes. Obes Surg. 2014;24 (9):1442-1446. doi:10.1007/s11695-014-1228-8

150. Brethauer SA, Aminian A, Rosenthal RJ, Kirwan JP, Kashyap SR, Schauer PR. Bariatric surgery improves the metabolic profile of morbidly obese patients with type 1 diabetes. Diabetes Care. 2014;37(3):e51-2. doi:10.2337/dc13-1736

151. Tang A, Milner KL, Tonks K, Campbell LV, Greenfield JR. Comment on Brethauer et al. Bariatric surgery improves the metabolic profile of morbidly obese patients with type 1 diabetes. Diabetes care 2014;37:e51-e52. Diabetes Care. 2014;37(11): e248-9. doi:10.2337/dc14-0578

152. Lannoo M, Dillemans B, Van Nieuwenhove Y, et al. Bariatric surgery induces weight loss but does not improve glycemic control in patients with type 1 diabetes. Diabetes Care. 2014;37(8): e173-4. doi:10.2337/dc14-0583

153. Middelbeek RJ, James-Todd T, Cavallerano JD, Schlossman DK, Patti ME, Brown FM. Gastric bypass surgery in severely obese women with type 1 diabetes: anthropometric and cardiometabolic effects at 1 and 5 years postsurgery. Diabetes Care. 2015;38(7): e104-5. doi:10.2337/dc15-0396

154. Maraka S, Kudva YC, Kellogg TA, Collazo-Clavell ML, Mundi MS. Bariatric surgery and diabetes: implications of type 1 versus insulin-requiring type 2. Obesity (Silver Spring). 2015;23 (3):552-557. doi:10.1002/oby.20992

155. Robert M, Belanger P, Hould FS, Marceau S, Tchernof A, Biertho L. Should metabolic surgery be offered in morbidly obese patients with type I diabetes? Surg Obes Relat Dis. 2015;11(4):798-805. doi:10.1016/j.soard.2014.12.016

156. Landau Z, Kowen-Sandbank G, Jakubowicz D, et al. Bariatric surgery in patients with type 1 diabetes: special considerations are warranted. Ther Adv Endocrinol Metab. 2019;10:20 42018818822207. doi:10.1177/2042018818822207

157. García-Caballero M, Valle M, Martínez-Moreno JM, et al. Resolution of diabetes mellitus and metabolic syndrome in normal weight 24-29 BMI patients with one anastomosis gastric bypass. Nutr Hosp. 2012;27(2):623-631. doi:10.1590/S021216112012000200041 
158. Reyes Garcia R, Romero Muñoz M, Galbis Verdú H. Bariatric surgery in type 1 diabetes. Endocrinol Nutr. 2013;60(1):46-47. doi:10.1016/j.endonu.2012.01.021

159. Moreno-Fernandez J, Chico A. Bariatric surgery results in patients with type 1 diabetes mellitus on continuous subcutaneous insulin infusion therapy. Endocrinol Nutr. 2016;63(10):571-572. doi:10.1016/j.endonu.2016.09.002

160. Rottenstreich A, Keidar A, Yuval JB, Abu-Gazala M, Khalaileh A, Elazary R. Outcome of bariatric surgery in patients with type 1 diabetes mellitus: our experience and review of the literature. Surg Endosc. 2016;30(12):5428-5433. doi:10.1007/ s00464-016-4901-2

161. Faucher P, Poitou C, Carette C, et al. Bariatric surgery in obese patients with type 1 diabetes: effects on weight loss and metabolic control. Obes Surg. 2016;26(10):2370-2378. doi:10.1007/s11695016-2106-3

162. Al Sabah S, Al Haddad E, Muzaffar TH, Almulla A. Laparoscopic sleeve gastrectomy for the management of type 1 diabetes mellitus. Obes Surg. 2017;27(12):3187-3193. doi:10.1007/s11695-017-2777-4

163. Vilarrasa N, Rubio MA, Miñambres I, et al. Long-term outcomes in patients with morbid obesity and type 1 diabetes undergoing bariatric surgery. Obes Surg. 2017;27(4):856-863. doi:10.1007/ s11695-016-2390-y

164. Mahawar KK, De Alwis N, Carr WR, Jennings N, Schroeder N, Small PK. Bariatric surgery in type 1 diabetes mellitus: a systematic review. Obes Surg. 2016;26(1):196-204. doi:10.1007/s11695-015-1924-z

165. Kirwan JP, Aminian A, Kashyap SR, Burguera B, Brethauer SA, Schauer PR. Bariatric surgery in obese patients with type 1 diabetes. Diabetes Care. 2016;39(6):941-948. doi:10.2337/dc15-2732

166. Ashrafian H, Harling L, Toma T, et al. Type 1 diabetes mellitus and bariatric surgery: a systematic review and meta-analysis. Obes Surg. 2016;26(8):1697-1704. doi:10.1007/s11695-015-1999-6

167. Chow A, Switzer NJ, Dang J, et al. A systematic review and meta-analysis of outcomes for type 1 diabetes after bariatric surgery. J Obes. 2016;2016:6170719. doi:10.1155/2016/6170719

168. Hussain A. The effect of metabolic surgery on type 1 diabetes: meta-analysis. Arch Endocrinol Metab. 2018;62(2):172-178. doi:10.20945/2359-3997000000021

169. Hanaire H, Bertrand M, Guerci B, Anduze Y, Guillaume E, Ritz P. High glycemic variability assessed by continuous glucose monitoring after surgical treatment of obesity by gastric bypass. Diabetes Technol Ther. 2011;13(6):625-630. doi:10.1089/ dia.2010.0203

170. Höskuldsdóttir G, Ekelund J, Miftaraj M, et al. Potential benefits and harms of gastric bypass surgery in obese individuals with type 1 diabetes: a Nationwide, Matched, Observational Cohort Study. Diabetes Care. 2020;43(12):3079-3085. doi:10.2337/ dc20-0388
171. Aminian A, Kashyap SR, Burguera B, et al. Incidence and clinical features of diabetic ketoacidosis after bariatric and metabolic surgery. Diabetes Care. 2016;39(4):e50-3. doi:10.2337/dc152647

172. Liakopoulos V, Franzén S, Svensson AM, et al. Pros and cons of gastric bypass surgery in individuals with obesity and type 2 diabetes: nationwide, matched, observational cohort study. $B M J$ Open. 2019;9(1):e023882. doi:10.1136/bmjopen-2018-023882

173. Wu P, Liu Z, Jiang X, Fang H. An overview of prospective drugs for type 1 and type 2 diabetes. Curr Drug Targets. 2020;21 (5):445-457. doi:10.2174/1389450120666191031104653

174. Ye X, Qi J, Wu Q, et al. Long-lasting hypoglycemic effect of modified FGF-21 analog with polyethylene glycol in type 1 diabetic mice and its systematic toxicity. Eur $J$ Pharmacol. 2016;781:198-208. doi:10.1016/j.ejphar.2016.04.025

175. Xie X, Yan D, Li H, et al. Enhancement of adiponectin ameliorates nonalcoholic fatty liver disease via inhibition of foxo1 in type i diabetic rats. J Diabetes Res. 2018;2018:6254340. doi:10.1155/2018/6254340

176. Vallianou NG, Stratigou T, Geladari E, Tessier CM, Mantzoros CS, Dalamaga M. Diabetes type 1: can it be treated as an autoimmune disorder? Rev Endocr Metab Disord. 2021. doi:10.1007/s11154-021-09642-4

177. Pourrajab B, Fatahi S, Sohouli MH, Găman MA, Shidfar F. The effects of probiotic/synbiotic supplementation compared to placebo on biomarkers of oxidative stress in adults: a systematic review and meta-analysis of randomized controlled trials. Crit Rev Food Sci Nutr. 2020;4:1-18. doi:10.1080/10408398. 2020.1821166

178. Sohouli MH, Fatahi S, Sharifi-Zahabi E, et al. The impact of low advanced glycation end products diet on metabolic risk factors: a Systematic Review and Meta-Analysis of Randomized Controlled Trials. Adv Nutr. 2020:nmaa150. doi:10.1093/ advances/nmaa 150

179. Enebo LB, Berthelsen KK, Kankam M, et al. Safety, tolerability, pharmacokinetics, and pharmacodynamics of concomitant administration of multiple doses of cagrilintide with semaglutide $2.4 \mathrm{mg}$ for weight management: a randomised, controlled, phase $1 \mathrm{~b}$ trial. Lancet. 2021;397(10286):1736-1748. doi:10.1016/S01406736(21)00845-X

180. Heymsfield SB, Coleman LA, Miller R, et al. Effect of bimagrumab vs placebo on body fat mass among adults with type 2 diabetes and obesity: a Phase 2 Randomized Clinical Trial. JAMA Netw Open. 2021;4(1):e2033457. doi:10.1001/ jamanetworkopen.2020.33457

181. Battaglia M, Ahmed S, Anderson MS, et al. Introducing the endotype concept to address the challenge of disease heterogeneity in type 1 diabetes. Diabetes Care. 2020;43(1):5-12. doi:10.2337/dc19-0880

\section{Publish your work in this journal}

Diabetes, Metabolic Syndrome and Obesity: Targets and Therapy is an international, peer-reviewed open-access journal committed to the rapid publication of the latest laboratory and clinical findings in the fields of diabetes, metabolic syndrome and obesity research. Original research, review, case reports, hypothesis formation, expert opinion and commentaries are all considered for publication. The manuscript management system is completely online and includes a very quick and fair peer-review system, which is all easy to use. Visit http://www.dovepress.com/testimonials.php to read real quotes from published authors. 